\title{
Cold Start on Low Compression Ratio Diesel Engine: Experimental and 3D RANS Computation Investigations
}

\author{
O. Laget, P. Pacaud and H. Perrin \\ Institut français du pétrole, IFP, Direction Techniques d'Applications énergétiques, \\ 1-4 avenue de Bois-Préau, 92852 Rueil-Malmaison Cedex - France \\ e-mail: olivier.laget@ifp.fr - pierre.pacaud@ifp.fr - herve.perrin@ifp.fr
}

\begin{abstract}
Résumé - Démarrage à froid d'un moteur Diesel à bas taux de compression : investigations expérimentales et numériques RANS tridimensionnelles - Les futures normes d'émission concernant les moteurs Diesel imposent une réduction importante des émissions polluantes à la source, avant les dispositifs de post-traitement. La réduction de "production" de NOx en maintenant de très bas niveaux d'émission de suie, de $\mathrm{HC}$ et de $\mathrm{CO}$ doit être effectuée sans dégrader le confort de conduite et en contrôlant la consommation de carburant et le bruit de combustion. La réduction du taux de compression (CR) est l'une des voies les plus prometteuses pour atteindre cet objectif. La contrepartie liée à la réduction de taux de compression des moteurs Diesel est qu'elle induit une dégradation des capacités au démarrage. En conséquence, une importante limitation à la réduction du taux de compression des moteurs Diesel réside dans l'exigence de démarrer par de basses températures. En effet, la réduction de la température ambiante pénalise la vaporisation du carburant et les capacités à l'auto-inflammation, d'autant plus à très basses températures $\left(-20^{\circ} \mathrm{C}\right.$ et inférieures) .

Ce papier présente le travail réalisé sur un moteur Diesel HSDI 4 cylindres doté d'un système d'injection "Common rail". Trois types d'investigation ont été utilisés. Des expériences ont été réalisées jusqu'à de très basses températures $\left(-25^{\circ} \mathrm{C}\right)$; des visualisations dans la chambre de combustion (vidéoscope) ont été faites et des calculs de dynamique des fluides ont été effectués pour des conditions de démarrage à froid.

La chambre de combustion a été adaptée afin d'abaisser le taux de compression (CR 13,7:1) en modifiant la forme du bol dans le piston. Dans un premier temps, les résultats expérimentaux obtenus avec le moteur à bas taux de compression sont comparés à ceux obtenus avec les moteurs originaux ayant un taux de compression conventionnel. Par la suite, les paramètres d'injection ont été totalement changés (masse de carburant, avance à l'injection, pression d'injection, etc.). Ceci permet de réduire de façon significative le délai de démarrage avec le moteur à bas taux de compression. Ainsi, les délais de référence obtenus avec le moteur ayant un taux de compression conventionnel peuvent être atteints. De plus, les effets liés aux différents paramètres géométriques de la chambre de combustion tels que la position des sprays par rapport à la bougie de préchauffage ont été étudiés et ont montré un large potentiel en ce qui concerne l'amélioration du comportement du moteur en conditions froides. Notamment, une réduction accrue des délais de démarrage peut être envisagée.
\end{abstract}

Afin de compléter les essais moteurs, des calculs de mécanique des fluides (CFD) ont été réalisés pour des conditions de démarrage à froid $\left(-20^{\circ} \mathrm{C}\right)$. Les résultats obtenus sont en bon accord avec les visualisations optiques et les mesures de pression cylindre. Des corrélations entre expériences et calcul 
fournissent des explications consistantes quant aux différents phénomènes intervenant lors d'un démarrage à froid.

\begin{abstract}
Cold Start on Low Compression Ratio Diesel Engine: Experimental and 3D RANS Computation Investigations - Diesel engines' future emission standards require greatly reducing the pollutant emissions directly at the exit of the engine before post-processing. The reduction of NOx "production" with very low levels of Particulate Matter (PM), HC and CO must be performed without damaging the drivability, and keeping fuel consumption and combustion noise under control. The reduction of the Compression Ratio $(C R)$ is one of the most promising ways to achieve this challenge. The counterpart of reducing Diesel engine $C R$ is the decrease in start ability. As a consequence, a stringent limitation of reducing Diesel CR is cold start requirements. Indeed, reduction of ambient temperature leads to penalties in fuel vaporization and auto-ignition capabilities, even more at very low temperature $\left(-20^{\circ} \mathrm{C}\right.$ and below).
\end{abstract}

This paper presents the work performed on a HSDI Common-Rail Diesel 4-cylinder engine. Three kinds of investigations were used: experiments performed at very low temperature (down to $\left.-25^{\circ} \mathrm{C}\right)$; incylinder imaging (videoscope) and three-dimensional Computational Fluid Dynamics (CFD) computations in cold start conditions.

The combustion chamber was adapted in order to reach a low compression ratio (CR 13.7:1) by modifying the piston bowl shape. First, experimental results obtained with a low $C R$ engine are compared with those obtained with the original conventional CR engine. Then, a complete recalibration of injection settings (fuel quantity and timing, injection pressure, etc.) was carried out. It allows one to significantly reduce start delay with a low CR engine and the reference start delay with the conventional $C R$ becomes reachable. In addition, effects of combustion chamber design such as spray position according to the glow plug were studied and show a great potential regarding behavior in cold conditions in particular, in order to reduce start delay again in such conditions.

In order to complete the engine tests, CFD calculations were performed during the starting operation in ambient cold conditions $\left(-20^{\circ} \mathrm{C}\right)$. The obtained results are in good agreement with optical observations and in-cylinder pressure measurements. Correlations between experiments and calculations give consistent explanations concerning the different phenomena occurring during cold start.

\section{DEFINITIONS, ACRONYMS, ABBREVIATIONS}

NOx Nitrogen Oxyde

HC Unburnt hydrocarbon

PM Particule Matter

CO Carbon monoxide

CR Compression Ratio

CFD Computational Fluid Dynamics

EGR Exhaust Gas Recirculation

ECU Engine Control Unit

TIC Transient Injection Conditions

TKI Tabulated Kinetics of Ignition

BDC Bottom Dead Center

TDC Top Dead Center

SOI Start Of Injection

SOIm Start Of Injection of the main injection

SOIp Start Of Injection of the pilot injection

RailP Fuel Pressure in the rail

Qpil Fuel quantity of the pilot injection
Qtot Total fuel quantity

str $\quad$ Stroke $\left(\mathrm{mm}^{3} / \mathrm{str}\right)$

CAD Crank Angle Degree

NTP Nozzle Tip Protrusion

PCyl Cylinder pressure

\section{INTRODUCTION}

Progress in technologies such as direct injection system development, turbocharging and EGR capabilities has made light duties equipped with a Diesel engine more and more fun to drive. Nevertheless, drastic reduction of pollutant emissions has to be achieved in order to reach the future emission standards. This can only be performed by optimizing the combustion process.

The key issue for a combustion system during a stabilized working point is to obtain the best trade-off between efficiency, raw emissions and noise levels at part load, and specific power and torque at full load. One of the ways to 
optimize the combustion is the reduction of the Volumetric Compression Ratio (CR). Indeed, a decrease in this allows reaching lower values of NOx/PM release, respecting $\mathrm{HC}$ and $\mathrm{CO}$ limits and keeping noise and fuel consumption under control [1]. In addition, at full load, higher specific power and torque may be obtained without increasing the maximum in-cylinder pressure. Nowadays, the engines used in passenger cars possess a volumetric compression ratio between 17:1 and 19:1. For future applications, lower volumetric compression ratios between 14:1 and 16:1 are currently being studied. The main drawback in reducing CR of engines for mass production is the working under cold conditions. Indeed, the starting operation and idle running in low ambient temperatures $\left(-20^{\circ} \mathrm{C}\right.$ and lower) can be greatly affected.

The present paper presents a study focused on the consequences of a reduction of CR from 17:1 to 13.7:1 on starting operations, and the optimization of the injection settings in order to allow a starting delay with the engine in the low CR (13.7:1) configuration almost as short as that in the original engine configuration (CR 17:1). Three different "tools" were used in this study: experimentation, calculation and visualization. All these ways of studying the combustion process and engine behavior are very complementary and very helpful in the challenge consisting of reducing the compression ratio of future Diesel engines and improvement of the combustion process.

Test benches give a guideline of calibration for low CR engines. In-cylinder visualizations highlight some consequences of vaporization and spray/wall interaction penalties such as wall wetting. CFD calculations in cold start conditions, which are in accordance with engine experimentations and visualizations, provide consistent explanations of the vaporization and auto-ignition processes.

\section{ENGINE EXPERIMENTAL SETUP}

\subsection{Test Bench Experiments and Combustion System Design}

The experiments were performed on a 4-cylinder PSA DW10 ATED 4 engine whose specifications are given in Table 1 below.

The measuring instruments in the combustion chamber induced a slight decrease in the Compression Ratio (CR) of the engine used for experiments compared with the production engine (17:1 instead of 18:1). As a consequence, the "nominal configuration" engine possesses a volumetric compression ratio equal to $17: 1$.

Moreover, all the tests done during the present study were performed with BERU metallic glow plugs.
Keeping the distance between the piston and cylinder head constant (same squish area), the volumetric compression ratio is reduced to $13.7: 1$, by enlarging the piston bowl. The increase in the bowl volume is obtained by performing a homothetic transformation of the profile (increase in both width and depth). This way of modifying the combustion chamber design allows one to keep the general shape of the nominal bowl. It should be noted that the injector and nozzle (like the whole injection system) are the same for both engine configurations (nominal and reduced CR). Consequently, in the low compression ratio engine, the fuel spray takes exactly the same position as in the original engine configuration (see Fig. 1).

TABLE 1

Cold start engine specifications

\begin{tabular}{|c|c|c|}
\hline & $\begin{array}{c}\text { Nominal } \\
\text { compression ratio }\end{array}$ & $\begin{array}{c}\text { Reduced } \\
\text { compression ratio }\end{array}$ \\
\hline Engine reference & \multicolumn{2}{|c|}{ PSA DW10 TED4 } \\
\hline Engine type & \multicolumn{2}{|c|}{4 cylinder, turbocharged, intercooler, direct injection } \\
\hline Cylinder head & \multicolumn{2}{|c|}{4 valves / cylinder } \\
\hline Bore $\times$ stroke & \multicolumn{2}{|c|}{$85 \mathrm{~mm} \times 88 \mathrm{~mm}$} \\
\hline Displacement & \multicolumn{2}{|c|}{$1998 \mathrm{cc}$} \\
\hline $\begin{array}{l}\text { Fuel injection } \\
\text { system }\end{array}$ & \multicolumn{2}{|c|}{$\begin{array}{c}\text { Common Rail Bosch CRI1 } \\
6 \text { holes, spray angle } 144^{\circ} \\
\text { Static hydraulic flow } 354 \mathrm{~cm}^{3} / 30 \mathrm{~s} / 10 \mathrm{MPa}\end{array}$} \\
\hline $\begin{array}{l}\text { Volumetric } \\
\text { compression ratio }\end{array}$ & $17: 1$ & $13.7: 1$ \\
\hline Bowl width & nominal & nominal - $4.3 \mathrm{~mm}$ \\
\hline Bowl depth & nominal & nominal - $1.7 \mathrm{~mm}$ \\
\hline Glow plug & \multicolumn{2}{|c|}{$\begin{array}{l}\text { Metallic self regulating type, } \\
\text { BERU ref. } 010022634411 \mathrm{~V}\end{array}$} \\
\hline
\end{tabular}

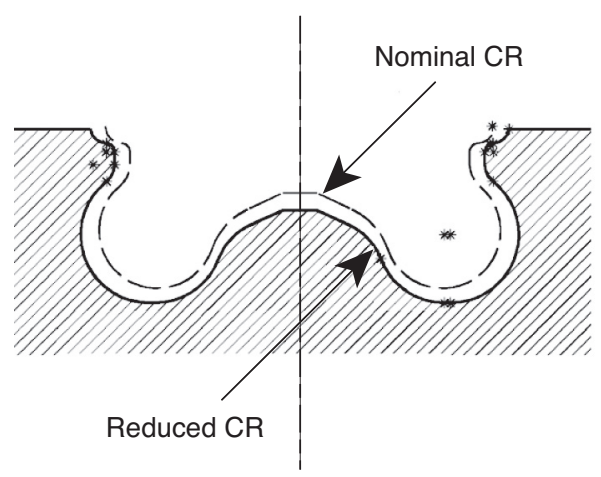

Figure 1

Combustion system (bowl technical definition) in nominal CR (dotted line) and reduced CR (continuous line). 
First, to check the accuracy of the injection system at very low temperature, specific tests were performed on the injection system apart. While the engine is driven by a dyno, the complete injection system (HP pump, rail, tube and injectors) removed from the engine is controlled by the ECU for several cartography breakpoints, representing a large range of injection pressures and injected quantities.

Injected quantities were measured and compared with the setpoints. A quite good correlation between targets and measurements is observed for main injection quantities (Fig. 2); for example, at $-20^{\circ} \mathrm{C}$, the gap between the target and measurement is less than $10 \%$. For "pilot" injection (less than $20 \mathrm{~mm}^{3} / \mathrm{str}$ during the starter operation), the correlation is less acceptable, with a lack of injection quantity of up to $25 \%$ compared with the setpoint. It should be noted that no significant gap was observed between the injectors.

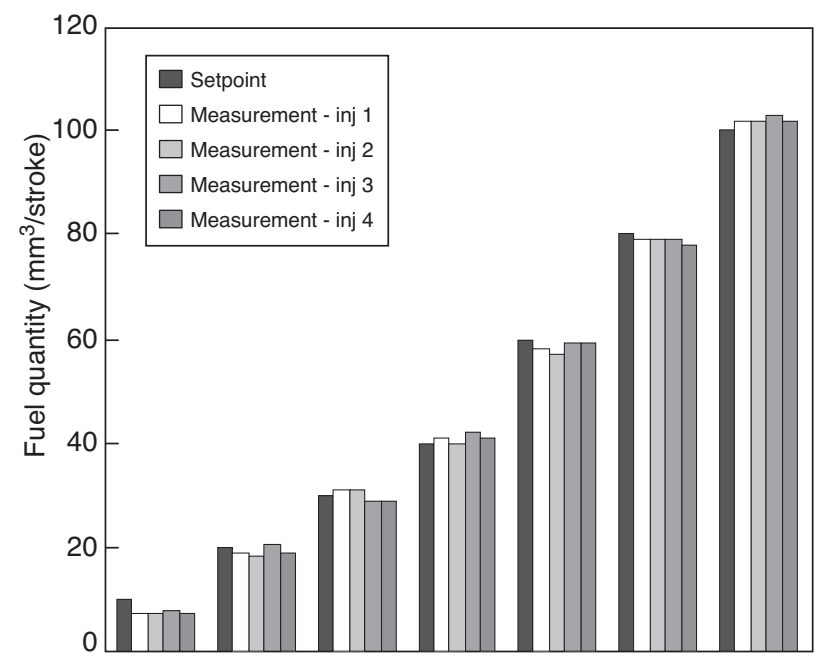

Figure 2

Comparison of injected fuel quantity per stroke at $-20^{\circ} \mathrm{C}$, between setpoint and measurement for each injector (injection pressure $30 \mathrm{Mpa}$ ).

All the tests were performed with a fuel able to withstand very low temperatures (Futura City Diesel DIC 29/34 from Fortum Oil) and a 5W30 engine oil as lubricant (Total Activa 9000).

\subsection{Test Bed and Measuring Equipment}

The engine was settled in a cold and dehumidified room whose ambient temperature can be varied from $-30^{\circ} \mathrm{C}$ up to $+25^{\circ} \mathrm{C}$. During engine running operations, ECU data acquisitions were performed by an ETAS Inca system.
Moreover, specific engine data were recorded such as: air, lubricant and water temperatures, temperature in the exhaust manifold close to the ports, lambda sensor in the exhaust line, and voltage and intensity of starter and glow plugs. Opacity is given by the AVL 439 system in the exhaust line. In addition, an optical shaft encoder determines the engine crank angle inside the cycle (TDC in particular). Each cylinder is equipped with a Kistler 605BB quartz crystal pressure transducer to measure the gas pressure in the combustion chamber. This transducer was implemented using a pipe machined in the cylinder head, but without a pressure wave penalty for tested engine speeds. Moreover, injection pressure was measured upstream of the injector. This allows one to check the pressure waves due to injector opening, and consequently to confirm that injection occurs.

\subsection{Soaking and Starting Procedure}

The electric starter of the engine - powered by the $12 \mathrm{~V}$ battery - is used to crank the engine. Two starters of specific power may be used, depending on the ambient temperature and required speed, mentioned in Table 2 . No significant difference in starter speed was highlighted between nominal and low CR configurations, even if acyclism is supposed to be lower with low CR. It should be noted that the engine is declutched during starting and warm up. Before each test, the engine and the fuel tank are soaked in the cold test bed for about 8 hours at the ambient required temperature. Because of higher thermal inertia, the battery is reloaded after each starting test for a whole day in order to ensure maximum and repetitive cranking power. As a consequence, three batteries are used alternatively for these tests.

The glow plugs of the production engine are used during all the tests. The preglowing duration can be adapted in function of the ambient temperature. It can last from $3 \mathrm{~s}$ to $16 \mathrm{~s}$, respectively, for temperatures from $+20^{\circ} \mathrm{C}$ to $-30^{\circ} \mathrm{C}$. The starter is switched on at the end of this preglowing duration. In the paragraphs below, the start delay is evaluated between starter launching and ECU "startbit" signal appearance, meaning that idle speed has just been reached.

TABLE 2

Starter speed and preglowing duration depending on ambient temperature

\begin{tabular}{c|c|c}
\hline Ambient temperature & Starter speed (rpm) & Preglowing duration (s) \\
\hline $20^{\circ}$ & 250 & 3 \\
\hline $10^{\circ}$ & 230 & 3 \\
\hline $0^{\circ}$ & 210 & 6 \\
\hline- & 190 & 1 \\
\hline- & 170 & 1 \\
\hline- & 160 & 1 \\
\hline
\end{tabular}

Finally, all the tests are performed at least twice in order to check the repeatability of the results. 


\section{NUMERICAL SETUP}

\subsection{Introduction}

The aim of the numerical part of the study is to provide information on the physical mechanisms occurring during the start of a Diesel engine with a low compression ratio in low temperature conditions $\left(-20^{\circ} \mathrm{C}\right)$. Accurate prediction of autoignition in the engine cycle or prediction of the engine start ability is not expected. A lot of parametric variations were performed and, in addition, some Chemkin computations were done in order to evaluate the required conditions.

\subsection{Description of the 3D CFD Code}

The three-dimensional simulations were performed using IFP-C3D code [2]. This solves the unsteady equations of a chemically reactive mixture of gases, coupled with the equations for a multi-component vaporizing fuel spray. This 3D CFD parallel (Open MP) code solves the Navier-Stokes equations using an ALE-extended (Arbitrary Lagrangian Eulerian, see [17-19] for more details concerning this model and its validation) finite volume method on unstructured and conformal hexahedral meshes. The code uses the well-known time-splitting decomposition and the Reynolds Averaged Navier-Stokes equations are solved without any Low-Mach approximation. The temporal integration scheme is largely implicit.

For turbulent combustion, the 3-Zone Extended Coherent Flame Model (ECFM3Z) is used [3]. The auto-ignition prediction and the influence of chemistry on reaction rates are provided by the TKI auto-ignition model [4], briefly described below. To obtain a realistic spray modeling during the injector needle motion, the Transient Injection Conditions (TIC) model [5] is used.

\subsection{Spray Modeling}

The spray of the injector is discretized into parcels (sets of droplets of the same characteristics). The radius of the injected droplets is equal to the effective radius of the injector hole. The turbulence model is $k-\varepsilon$ and the Wave/FIPA model [6] is used to model the evaporation and the break-up. It should be specified that all the parameters of the injection model were fixed in order to get a good agreement with experimental measurements and visualizations performed in "normal" running conditions. For the present study (cold start, low temperature) the parameters of this model were not modified due to a lack of experimental visualization for the present running conditions. Evolutions of these spray parameters for such conditions may increase the accuracy of the model for cold start representation.

\subsection{Liquid Fuel Film Model}

The liquid fuel film on walls is modeled using an in-house Lagrangian model based on the O'Rourke and Amsden [7, 8] model for the formation, evaporation and splashing. This model was improved using the work of Xu and Han [9, 10]. The modeling of liquid film dynamics takes into account the spray impact, the surface motions and the gas evolutions in the vicinity of the film.

The interaction with the spray induces, of course, mass evolution, but changes in terms of energy and tangential momentum too. Moreover, submodels were introduced in order to take into account droplet rebound and splashing. The interaction between the liquid film and the walls depends on heat fluxes and adherence conditions. Fluid motion close to the film acts on it through heat fluxes and shear constraints. Finally, the evaporation induces a decrease in film mass.

\subsection{Ignition and Combustion Modeling}

For compression-ignited internal combustion engines, combustion modeling relies on the combination of two models. The ECFM-3Z model describes the turbulent mixing in each mesh cell and provides the local thermodynamic conditions and species concentrations for the TKI auto-ignition model. This represents the chemical kinetics related to the combustion process. After the start of combustion, the representation of the turbulent mixing by the ECFM $3 Z$ model allows one to define the local conditions in order to represent the combustion progress well.

\subsubsection{The ECFM3Z Model}

A complete description of the ECFM3Z model is available in [3] for compression-ignition operating conditions. This model allows one to correctly represent the local mixing process occurring in the combustion chamber before autoignition and during and after combustion.

\subsubsection{The TKI Model}

Auto-ignition is computed thanks to the TKI (Tabulated Kinetics of Ignition) model (more extensively described in [4]). It relies on tabulated auto-ignition quantities issued from detailed chemistry calculations performed with the Senkin code (part of the Chemkin package). Databases have been built for a wide range of thermodynamic conditions representative of cool flame ignition as well as main ignition, using a detailed mechanism (416 species, 1992 reactions) for different $n$-heptane/iso-octane mixtures issued from the DCPR laboratory (Département de Chimie Physique des Réactions [11]). The 3D model variables are calculated once and for all for a large range of initial thermodynamic conditions and are stored in lookup tables. The fresh (or unburnt) gas quantities that are used as input parameters of the auto-ignition lookup tables are the temperature, the pressure, the fuel-air equivalence ratio, the rate of dilution 
and the octane number. The authors are conscious that the precision of the database can be improved for the ranges of low temperatures and pressures observed in the present study. This improvement may lead to an increase in the accuracy of the computation in the case of cold start.

\subsection{Computation Assumptions}

Several assumptions were fixed in order to decrease the computation time. The aim is to reduce the computational domain, keeping a realistic level of precision.

\subsubsection{Computational Domain}

Neglecting the valves and their recesses and taking into account that the multi-hole injector is centered (the glow plug consideration is exposed lower) allows one to assume that the combustion chamber is not really axi-symmetric but possesses periodic characteristics. In most cases this assumption allows one to consider a computational domain representing only an angular sector of the chamber corresponding to the area concerning only one spray of the injector.

Here, for cold start considerations, the glow plug has to be taken into account. Making the assumption that the influence of the plug is confined to its direct neighborhood (heating due to shining is neglected), added to the fact that the aim of the present study is to understand the mechanisms inducing the first combustion still allow one to consider a periodic combustion chamber: in fact, the modeled chamber will possess several glow plugs. In order to represent the location of the plug better versus the sprays, an angular sector corresponding to the area concerning 2 sprays is considered. As the injector possesses 6 holes, the angle of the combustion chamber sector is equal to $120^{\circ}$. The computational mesh is shown in Figure 3. It can be noticed that the plug is represented by a specific wall with a given temperature (about $1000^{\circ} \mathrm{C}$ ) that can be varied. The meshes were realized using Icem-CFD Hexa. Their size varies between about 52000 (start of computation) and 41000 hexas (during injection and start of combustion). The changes in mesh size are performed using a remapping algorithm.

\subsubsection{Blow-by and Compression Ratio}

The piston shape was specifically designed in order to obtain a combustion chamber with a nominal compression ratio of 13.7:1. In order to "take into account" the significant blow-by existing during the first engine cycle in cold start conditions, and as no blow-by model was available at the beginning of this study, the nominal compression ratio used for computations was reduced to 12.5:1 (equivalent value deduced from 1D computations) by adding a crown at the outlying area of the computational domain in order to reproduce the experimental in-cylinder pressure trace.

This means of mimicking blow-by allows one to keep the original distance between the cylinder head and piston and

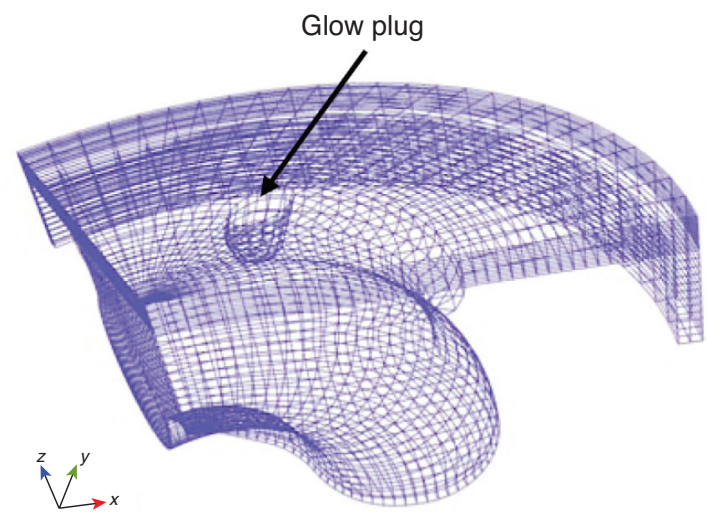

Figure 3

Mesh of the computational domain.

the additional fresh air in the chamber (in the crown) is not located in the area of spray and will not influence the local fuel-air equivalence ratio in the bowl and close to the plug. But this methodology, even if it allows one to represent the loss of in-cylinder pressure well at the Top Dead Center due to blow-by, may not allow one to represent the mean incylinder temperature well. Indeed, the air mass heated during compression is larger in computations than in experiments. Moreover, the heat fluxes between cold walls and fluid is larger due to the increase in cylinder liner area in the crown. This is a first step for modeling and a blow-by model is under development in order to increase the accuracy of the representation.

\subsubsection{Fluid Dynamics and Injection}

The intensity of fluid motion in the cylinder is assumed to be low. The filling ratio is assumed to be equal to 1 . However, in reality the pressure drop due to the inertia of the air in all the intake manifold may induce a lower filling ratio (around 0.95). The computation starts at the Bottom Dead Center (BDC). The initial pressure is fixed at $0.1 \mathrm{MPa}$ and the initial swirl motion is set equal to 0.2 for an engine speed of 170 RPM. The specifications of the injector are the same as for engine tests (Bosch CRI1 with spray angle equal to about $144^{\circ}$ and 6 holes). The instantaneous flow rate is fitted on experimental data. The injected fuel is a single-component model possessing almost the same characteristics as experimental fuel at conventional temperatures (the fuel surrogate possesses a slightly different distillation curve compared with the experimental one and needs more heating for evaporation, inducing limitations in terms of representativity of the numerical model). Computations were performed with same injected mass as experiments (small differences in terms of injected volume of fuel). Even if the injected energy is not really the same as in experiments (very small 
difference in terms of the fuel-air equivalence ratio) it allows one to represent well the first steps of cold start and the different phenomena involved in such conditions.

\subsubsection{Initial and Boundary Conditions}

It may be stated that the initial and boundary conditions cannot be as close as one would wish to those of the experimental cycle to be modeled because of a large number of unknowns.

As said above, the computation starts at BDC. At this time, the chamber is filled with pure, fresh air at the external temperature $\left(-20^{\circ} \mathrm{C}\right)$. The piston, cylinder head and cylinder liner temperatures are similar. Only the walls of the glow plug are heated at a temperature of about $1000^{\circ} \mathrm{C}$.

The engine is supposed to be cranked by the starter at $170 \mathrm{rpm}$. During the modeled first cycle, this engine speed is supposed to be constant even if a combustion occurs. It should be specified that here, when the first engine cycle is modeled, the walls and the fluids (air and fuel) are supposed to be at external nominal temperature and the chamber is filled with pure air. In reality, the first combustion occurs in general during the second or third engine cycle where the walls may have been heated (first compression and friction) and there may be some fuel in the chamber from the previous unburnt cycles. Indeed, as presented below, during the first cycle a lot of fuel is trapped in the liquid film on the piston walls. This fuel is not available during the first cycle but the evolution of the liquid film during the exhaust phase of the first cycle is unknown. As a consequence, future work will consist of the computation of the first two cycles in order to give indications of the initial conditions of the second engine cycle, concerning trapped fuel mass (liquid and gas) remaining from the previous cycle.

\section{OPTICAL SETUP}

In order to understand phenomena such as fuel wall wetting during the cranking operation in low compression ratio (CR 13.7:1) better, a camera "videoscope" (AVL Pulnix TMC9700 ) is used. The frequency of shot acquisition is $10 \mathrm{~Hz}$; thus, this type of camera enables only one shot per engine cycle at starter speed. Connected with the optical shaft encoder mentioned above, the timing of the shot can be defined in the cycle. Moreover, as the camera is nonintensified, a stroboscope (supplier: $E G \& G$ ) has to be used as a source of light to illuminate the combustion chamber with good timing.

For these optical tests, a specific cylinder head was installed on the engine. This is a production DW10 cylinder head (identical injector location and swirl level) where the following modifications were managed:

- two entrances were machined one under the other, in one of the 4 cylinders (cylinder No. 3 ), in order to receive as

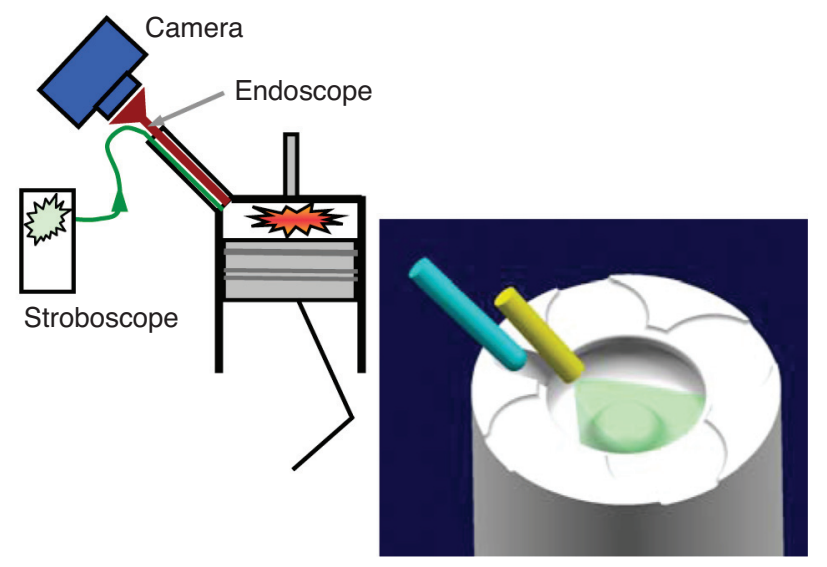

Figure 4

Optical setup with adapted cylinder head.

preferred the endoscope or the source of light. In the tests presented in this paper, the source of light is located in the top entrance while the endoscope is located in the bottom one;

- as this cylinder head is a prototype one, no glow plug is mounted in any cylinder. So combustion is damaged in cold conditions.

In this configuration, the piston re-entrant of the cylinder No.3 was machined to facilitate optical entries when the piston is near TDC. In order to keep constant the clearance volume value of this cylinder, bowl volume was slightly reduced by a homothetic law. As a result, all cylinders have the same compression ratio, 13.7:1. This setup is illustrated in Figure 4.

\section{KEY ISSUES IN COLD OPERATION FOR LOW COMPRESSION ENGINE}

\subsection{Vaporization and Estimation of In-cylinder Gas Temperature}

Compared with a standard compression ratio, the main problem with a low compression ratio engine is the reduction of pressure (see Fig. 5), and consequently the reduction of cylinder temperature during the compression stroke and then at Top Dead Center (TDC). This reduction of temperature causes penalties in the vaporization process. So it is relevant to estimate TDC gas temperature in low CR 13.7:1 and compare it with the TDC gas temperature in a nominal configuration engine (CR 17:1).

To estimate the TDC temperature (with only air charge), a simplified DW10 engine model was built with AMESim - IFP Engine 0-D code developed by IMAGINE and IFP. The first cycle during the cranking phase is operated at 


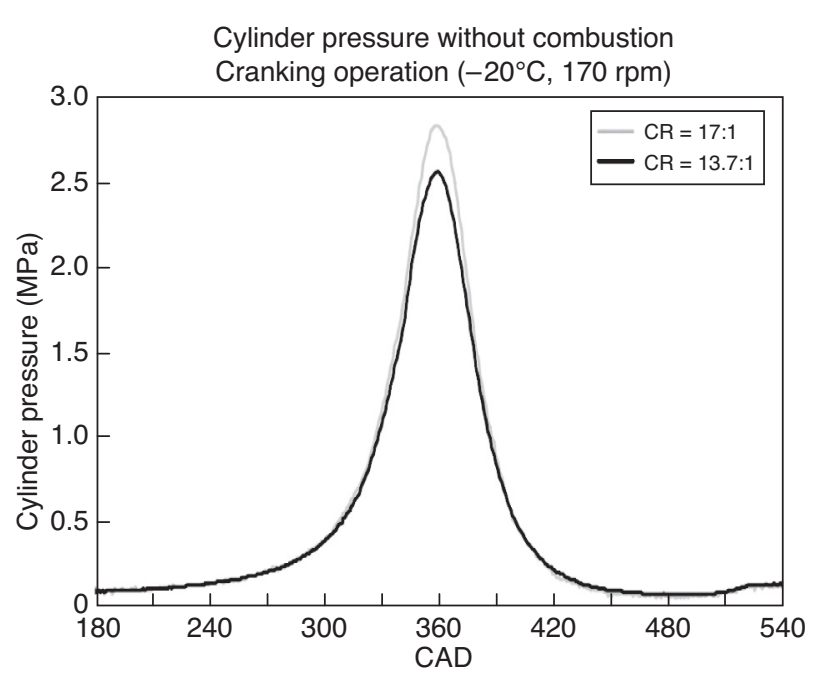

Figure 5

Cylinder pressure during compression for compression ratios 17:1 and 13.7:1 (at $-20^{\circ} \mathrm{C}$ ). The first complete cycle during cranking operation (with injection and without combustion) is represented.

$170 \mathrm{rpm}$ for an ambient temperature of $-20^{\circ} \mathrm{C}$. This model takes into account the main phenomena involved in cold start operation to estimate approximately the temperature of the compressed gas: wall heat losses, reduction of air filling due to the unadapted distribution diagram at very low engine speed, and blow-by leakage [12].

\subsubsection{Wall Heat Losses}

To estimate the heat losses during pure compression (without injection/combustion) $Q_{\text {losses }}$, the Woschni correlation was used and is summarized by Equations (1) to (3) below:

$$
\begin{gathered}
A_{1}=C_{1} \cdot V_{P} \\
h_{\text {conv }}=130 \cdot \frac{\left(p \cdot A_{1}\right)^{0.8}}{T^{0.53} \cdot B^{0.2}} \\
Q_{\text {losses }}=\int_{\text {cycle surfacesi }} \sum_{\text {conv }} \cdot S_{i} \cdot\left(T-T_{i}\right) \cdot d \theta
\end{gathered}
$$

with: $V_{p}$ : Average speed of the piston;

$C_{1}$ : Woschni heat exchange coefficient;

$T, p$ : Respectively, gas temperature and gas pressure;

$B$ : Cylinder bore;

$S_{i}, T_{i}$ : Respectively, surface and temperature of various surfaces of the combustion chamber.

For the first compression cycle during starter operation, cylinder and piston walls are approximately at the soaking temperature, $T_{i}=-20^{\circ} \mathrm{C}$. Because the starter speed is much lower $(\sim 170 \mathrm{rpm})$ than during "conventional" combustion engine running, coefficient $C_{l}$ has to be fitted.

Specifically to estimate the $C_{1}$ coefficient, engine tests were performed at ambient temperature $+20^{\circ} \mathrm{C}$ on a single cylinder based on PSA DW10 ATED 4 geometry equipped with a specific measurement of blow-by, at very low engine speed. At the same time, CFD calculations of the cooling circuit were performed on the same engine basis and allowed knowing the temperature of the various walls of the combustion chamber for the same operating point. These tests and these calculations, performed at ambient temperature, are not described in detail in this paper. By using Equations (1) to (3) with the estimation of temperature walls (by CFD calculation), air filling and blow-by (by the engine tests) in this single-cylinder engine operation, the Woschni coefficient $C_{1}$ was estimated to be around 5 in ambient conditions. As this $C_{1}$ coefficient is governed above all by the gas movement in the proximity of cylinder walls and then by piston speed and swirl - and not by the gas temperature, the same value of $\mathrm{C} 1=5$ was supposed to be approximately the same in warm and cold conditions at the same engine speed and it was retained for the cold starting phase in the multi-cylinder tests.

\subsubsection{Air Filling and Effective Compression Ratio}

The simplified DW10 engine model developed with AMESim - IFP Engine code was used to estimate air filling during starter operation. Indeed, due to very low engine speed, air

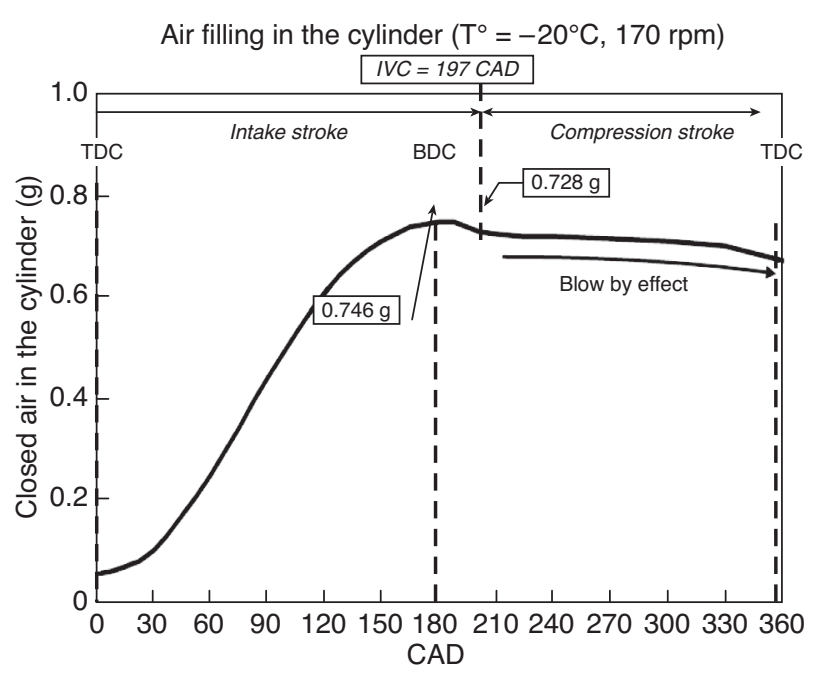

Figure 6

Air filling profile during intake and compression for $\mathrm{CR}$ 13.7:1. Ambient temperature is $-20^{\circ} \mathrm{C}$. 
filling is penalized by the leakage due to the Late Intake Valve Closing (IVC): cylinder air is leaving the cylinder during the beginning of the compression (see Fig. 6).

As a result, for a $-20^{\circ} \mathrm{C}$ operation point at $170 \mathrm{rpm}$, maximum air quantity is $746 \mathrm{mg}$ at the end of the compression stroke, but only $728 \mathrm{mg}$ at the IVC. This causes a decrease in the effective compression ratio and then in temperature at TDC when combustion is supposed to occur.

\subsubsection{Blow-by}

With air filling and wall heat losses previously estimated, blow-by is calculated in cold conditions during the starting operation. Blow-by is implemented in AMESim - IFP Engine 0-D code as a leakage surface. This surface is fitted in order to equalize the calculated pressure by AMESim and the measured pressure in the engine tests during the starting operation $(170 \mathrm{rpm})$. As a result, the blow-by process is estimated to assume a lack in cylinder pressure of almost $0.35 \mathrm{MPa}$ and a lack in cylinder temperature of $24 \mathrm{~K}$ at TDC for the engine test at $-20^{\circ} \mathrm{C}$.

Then, cylinder peak temperature calculation gives about $555 \mathrm{~K}$ for the engine test with $\mathrm{CR}$ 13.7:1 at $170 \mathrm{rpm}$ and ambient temperature $-20^{\circ} \mathrm{C}$. With the same methodology and the same operating point, the value for the CR 17:1 is close to $587 \mathrm{~K}$. This temperature reduction of around 30 to $35 \mathrm{~K}$ causes penalties for complying with a complete fuel vaporization by heat transfer between air charge and fuel droplets; as a result, the global vaporized fuel rate decreases, and conditions for successful combustion are all the more damaged. Moreover, the reduction of temperature and pressure at TDC with reduced $\mathrm{CR}$ tends to increase ignition delay [12], so as to be not compatible with the starting operation and to require further starting aid equipment (higher temperature and fast-response glow plug, etc.) [13], as we can see below.

\subsection{Auto-Ignition Analysis using CHEMKIN}

In order to understand the required conditions to get autoignition in cold conditions, several detailed kinematic chemistry calculations were performed using Senkin (part of the Chemkin package) with $n$-heptane. This fuel is characterized by almost the same general behavior as gas oil in terms of auto-ignition. Even if it does not allow one to take into account the lighter components of a conventional Diesel fuel, that certainly slightly affects the auto-ignition delay, the present results give several indications to understanding the main mechanisms of cold start auto-ignition.

About 3500 computations were performed with different sets of the following parameters:

- the pressure was taken between 1.9 and 2.9 $\mathrm{MPa}$ (the experimental starts of combustion occur in this interval of pressure);
- the temperature was chosen between 300 and $1200 \mathrm{~K}$ (53 different temperatures were studied);

- the fuel-air equivalence ratio was varied between 0.2 and 0.7 (computations show that the local fuel-air equivalence ratio in the vicinity of the glow plug does not exceed 0.7 ).

For each of the computed cases, the auto-ignition delay for cool flame and main ignition were deduced (maximum local gradient on temperature time evolution, see Fig. 7).

The value of those delays allows one to quantify the autoignition potential. Indeed, the smaller the delay, the higher the auto-ignition potential. On the contrary, too long a delay can be interpreted as an impossible auto-ignition. In Figure 8 to Figure 11, the white areas represent the low potential of auto-ignition and in contrast, the darker areas show the set of parameters where auto-inflammation will certainly occur.

Several observations can be made:

- the cool flame auto-ignition delay is not really sensitive to the fuel-air equivalence ratio. In fact, only the main combustion delay is sensitive to the fuel-air equivalence ratio. Thus, increasing the fuel-air equivalence ratio allows one to decrease the main ignition delay;

- in the studied pressure interval, there is no (or very small) influence of pressure on cold flame auto-ignition delay;

- for all the cases, in terms of fuel-air equivalence ratio and pressure, the lowest temperature required to get autoignition is of the order of $660 \mathrm{~K}$.

All these observations seem to indicate that, in cold start conditions $\left(-20^{\circ} \mathrm{C}\right)$, auto-ignition can occur only in the vicinity of the glow plug. Indeed, the minimal temperature

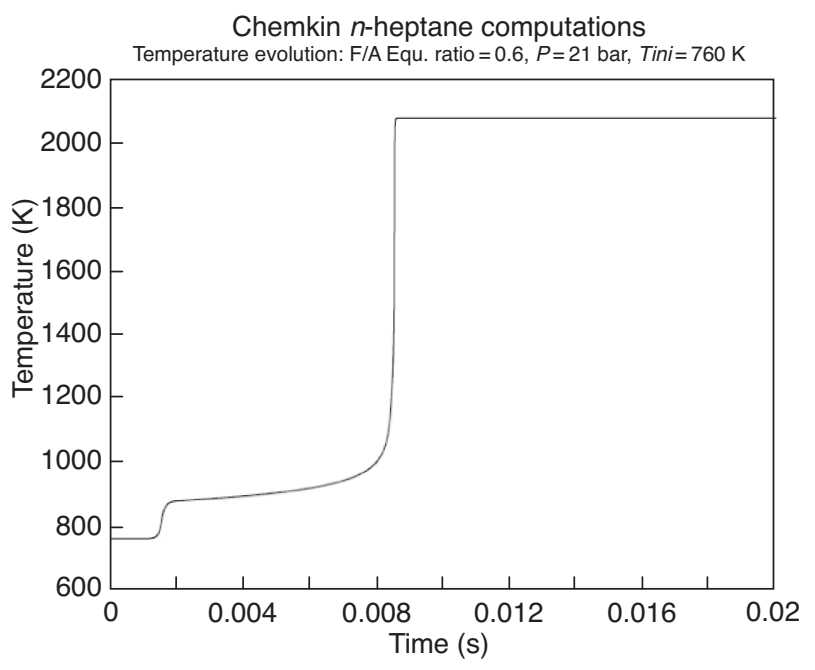

Figure 7

Temperature evolution, Chemkin computation at fuel-air equivalence ratio $=0.6, P=2.1 \mathrm{MPa}, T=760 \mathrm{~K}$. 


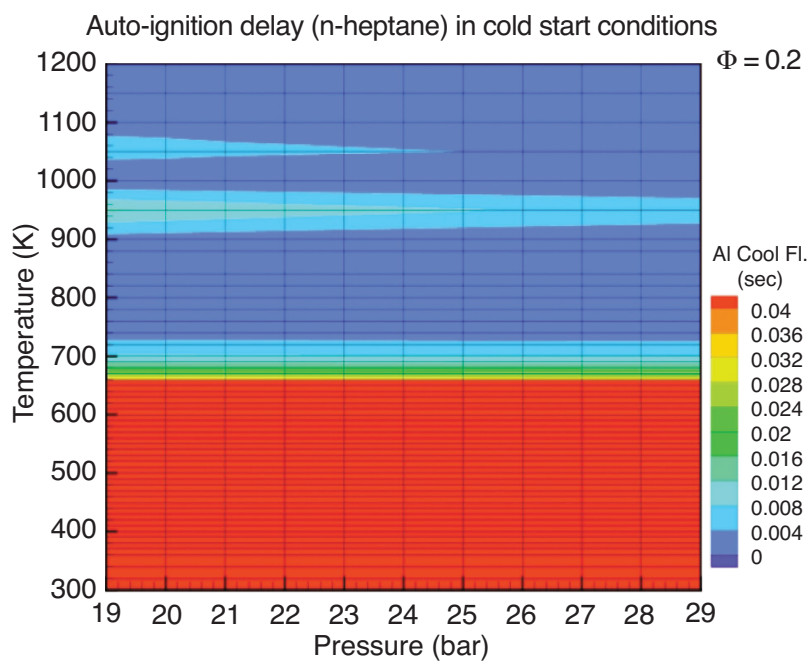

Figure 8

Auto-ignition delay for cool flame mapped versus pressure and temperature for fuel-air equivalence ratio $=0.2$.

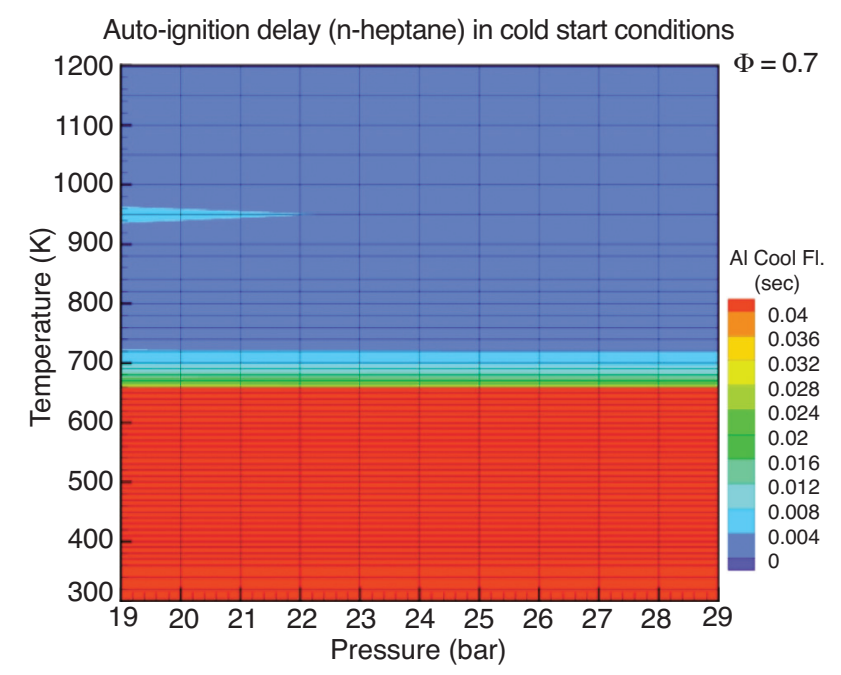

Figure 10

Auto-ignition delay for cool flame mapped versus pressure and temperature for fuel-air equivalence ratio $=0.7$.

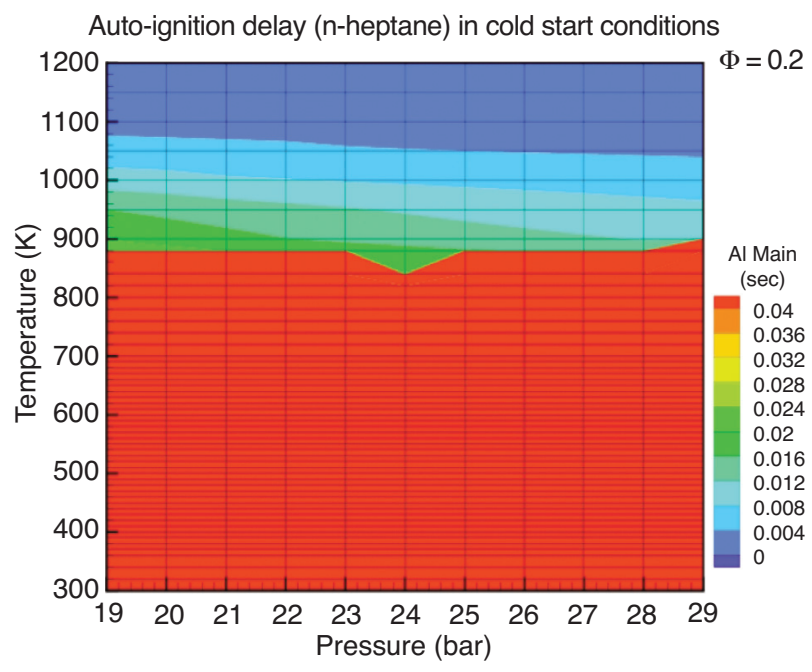

Figure 9

Auto-ignition delay for main ignition mapped versus pressure and temperature for fuel-air equivalence ratio $=0.2$.

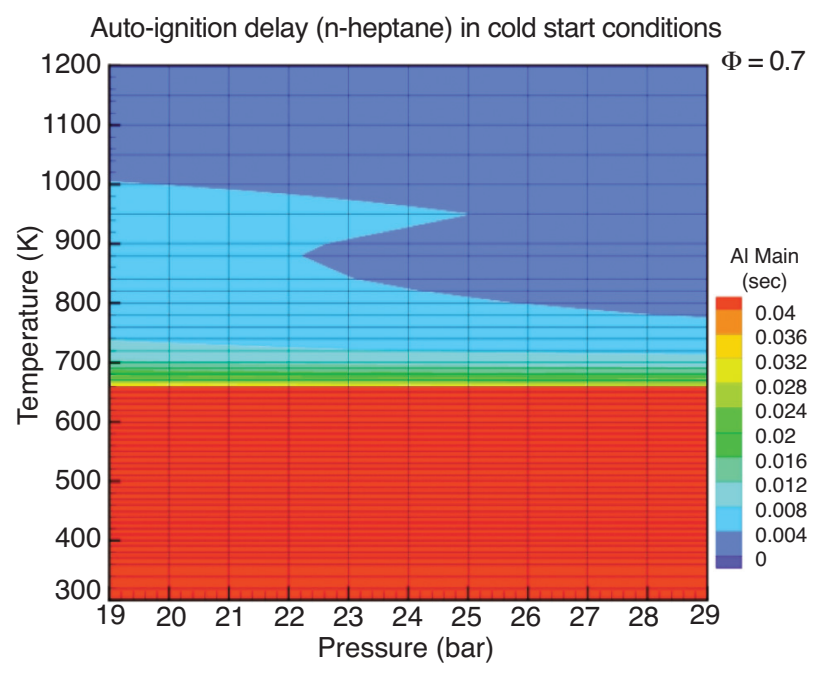

Figure 11

Auto-ignition delay for main ignition mapped versus pressure and temperature for fuel-air equivalence ratio $=0.7$. required can be reached only close to the plug. Moreover, a low fuel-air equivalence ratio (of the order of 0.2) is enough to obtain an auto-ignition.

These two critical phenomena - limitation of fuel vaporization by temperature reduction, penalty in auto-ignition processes - and the subsequent behaviors on running engine operation in very cold conditions - start delay increase, erratic combustion stability - have to be studied in more detail in order to be minimized, to make the compression ratio consistent for future applications.

\section{ENGINE TEST RESULTS AND DISCUSSION}

\subsection{Starting Reference with Nominal CR Engine}

During the present part of the study, the engine with a nominal compression ratio (17:1) is started with the injection settings of the production engine. During the starting operation, injection settings evolve with engine speed (between 150 and $1000 \mathrm{rpm}$ ) according to calibration breakpoints. 
The results are summarized in Table 3. Start delays globally conform to references for this technology (metallic glow plug).

TABLE 3

Start delay with nominal compression ratio (17:1)

\begin{tabular}{l|c|c|c|c|c}
\hline \multicolumn{7}{c}{ Engine starting - CR 17:1 } \\
\hline Soaking temperature & $20^{\circ}$ & $0^{\circ}$ & - & - & - \\
\hline Starting delay & 1.1 & $1.55 \mathrm{~s}$ & 1.55 & 2.5 & 5.7 \\
\hline
\end{tabular}

Start delay is mainly explained by a lack of combustion during the starting phase (Fig. 12).

At very low temperature $\left(-20^{\circ} \mathrm{C}\right.$ and below), the speed rise is slower because of an inadequation between IMEP (erratic combustion) and FMEP (higher lubricant viscosity). Accordingly, this paper focuses on combustion in cold conditions, especially during the cranking phase, and so at very low engine speed (150-250 rpm).

\subsection{Starting Operation with Low Compression Ratio and Reference Injection Settings}

The same injection settings (quantity, timing, rail pressure) are performed in CR 13.7:1 as done on the nominal CR engine in order to quantify the effect of the reduction of temperature and pressure in the combustion chamber during the starting operation. Engine start at a normal ambient temperature $\left(20^{\circ} \mathrm{C}\right)$ is studied in more detail below. The injection settings and the speed profile for this temperature are given in Figure 13.

At $20^{\circ} \mathrm{C}$, the engine start is dramatically damaged (start delay: $17.5 \mathrm{~s}$ ), with erratic cycle-to-cycle and cylinder-tocylinder combustions, which leads to an extremely slow speed increase and an unacceptable vibration level.

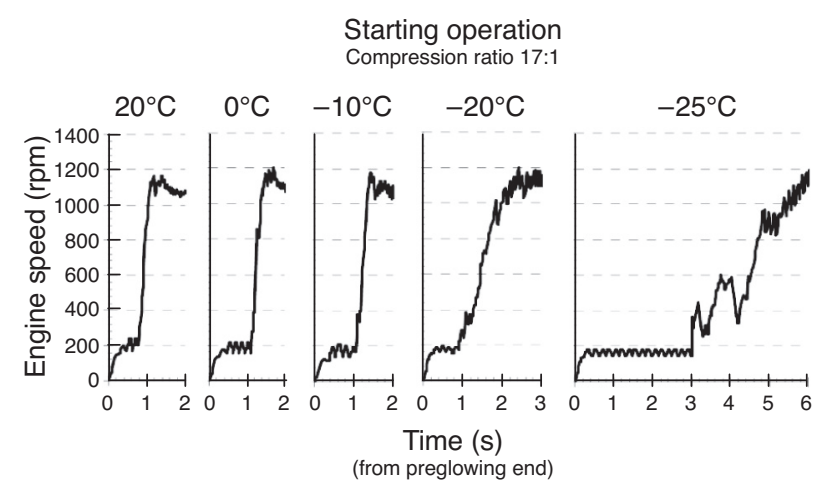

Figure 12

Engine starting after preglowing duration, $C R=17: 1$.
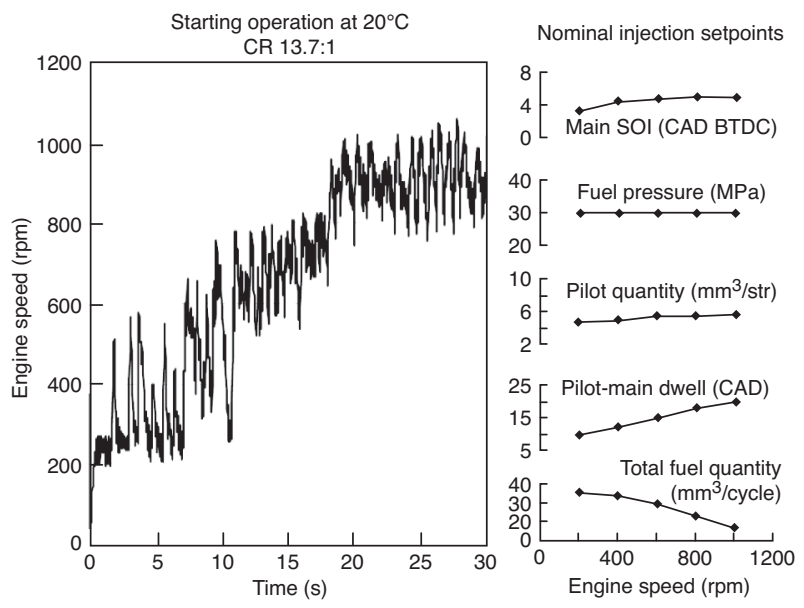

Figure 13

Starting operation at $20^{\circ} \mathrm{C}$, with $\mathrm{CR} 13.7$ engine. Injection setpoints are unchanged regarding production CR 17:1 engine.

As expected, lower ambient temperature is inclined to exacerbate these penalties; starter operation becomes longer with lower temperature so that starting is impossible for temperatures below $0^{\circ} \mathrm{C}$.

These penalties are symptomatic of two main phenomena:

- the quantity of vaporized fuel is insufficient, due to the low pressure and temperature;

- the quantity of vaporized fuel near the glow plug is not adapted at the precise time when auto-ignition could occur (in-cylinder optimum conditions, near TDC).

The first phenomenon and subsequent wall wetting $[8,8]$ is underlined by shots performed in the engine in one cylinder during starter operation, for a temperature of $5^{\circ} \mathrm{C}$. Figure 14 shows the impact of two injector sprays resulting from injections of previous engine cycles (without combustion). As cycles with injection (without combustion) are occurring, the liquid film is progressively covering up the bowl area while the piston is going up (Fig. 15).

At the end of the cycle, later than main combustion occurs, combustion seems to come back locally (Fig. 16). This may be explained by vaporization and burning of fuel spread on the piston wall (liquid pool firing).

These phenomena show that one of the main key issues for low compression applications is the difficulty of vaporizing fuel and the subsequent wall wetting.

To conclude, drastic reduction of the compression ratio without optimization of injection settings or without an upgrade in combustion chamber design or cold start devices technology - such as the glow plug - leads to an unacceptable cold start behavior even in moderate cold conditions. 


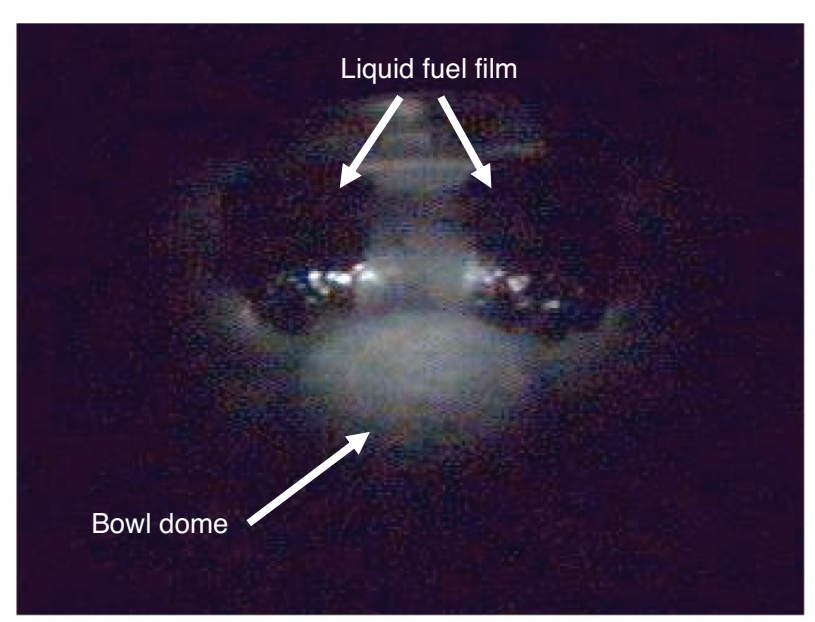

Figure 14

Cranking engine. Impact of 2 injector sprays, phase at $800 \mathrm{rpm} / 5^{\circ} \mathrm{C}$, with CR 13.7 on the bowl.

\subsection{Optimization of Injection Settings During Starting Operation at Temperature $-20^{\circ} \mathrm{C}$}

The methodology used for the cold start optimization is based on separate variations of each injection setpoint: start of pilot injection (SOIp), start of main injection (SOIm), rail pressure (RailP), pilot fuel quantity (Qpil) and total fuel quantity (Qtot). Thus, the impact of each injection parameter on start delay is evaluated separately. In order to do that, the variation profile of injection parameters versus engine speed is the same in the low CR configuration as in the nominal one, and each parametric variation consists of an offset applied to the whole engine speed range (150-1000 rpm). The results are discussed below. The value of the parameters is mentioned at $170 \mathrm{rpm}-e . g$. approximately during engine cranking. Then, depending on start delays, for each injection parameter, the setpoint values may be fitted on each engine speed if necessary.

The results obtained with this methodology are presented below for the temperature of $-20^{\circ} \mathrm{C}$.

\subsubsection{Main Injection Timing}

As mentioned before, one key for a successful engine start consists of as complete as possible a vaporization. As vaporization is governed by pressure and temperature in the cylinder, the higher the temperature during the injection event, the better vaporization is supposed to be. Obviously, temperature (and pressure) is not the unique parameter to take into account for the injection strategy; the instantaneous swirl value, the relative position between the spray and the bowl, and between the spray and the glow plug, seem to be important parameters too.
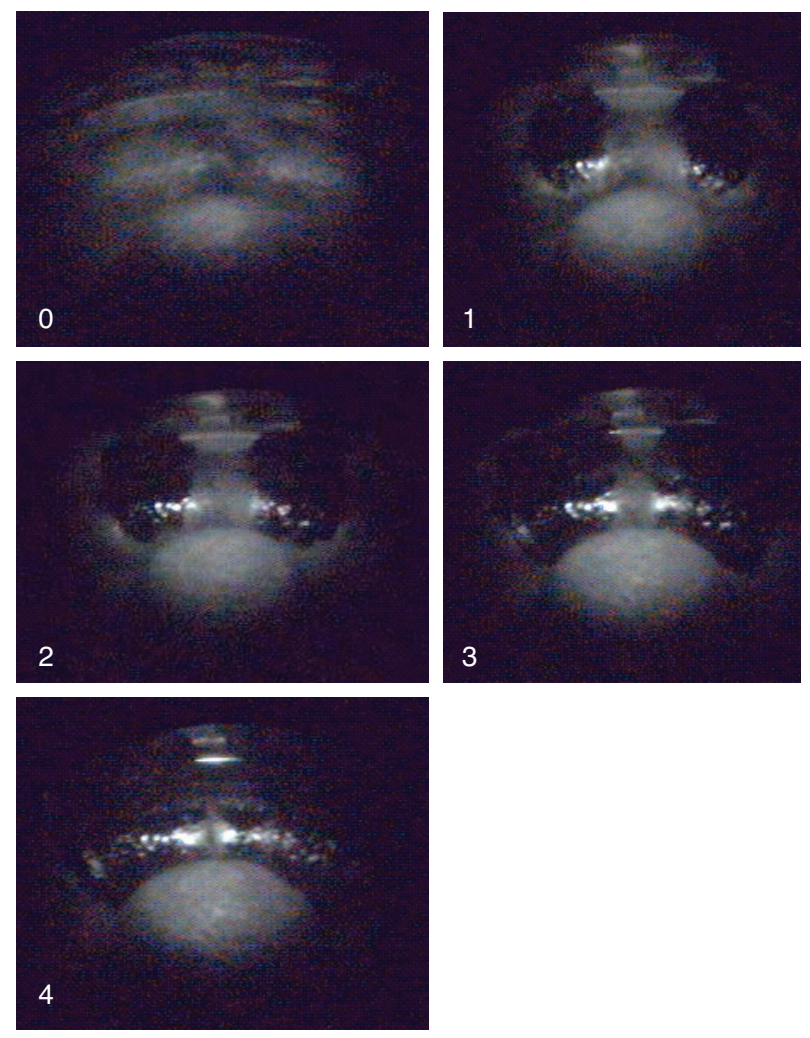

Figure 15

Cranking phase at $800 \mathrm{rpm} / 5^{\circ} \mathrm{C}$, with CR 13.7 engine. Liquid film is covering up bowl area.

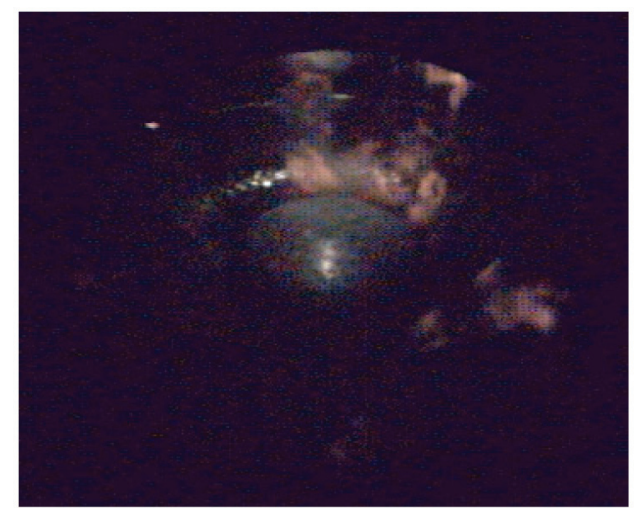

Figure 16

Cranking phase at $800 \mathrm{rpm} / 5^{\circ} \mathrm{C}$, with $\mathrm{CR} 13.7$ engine. Local combustion (49 CAD after TDC).

The injection timing is tuned in order to enhance temperature conditions during the injection process. Figure 17 shows that an earlier injection timing than the nominal one allows the engine to start, which is not the case with the initial settings (late timing). 


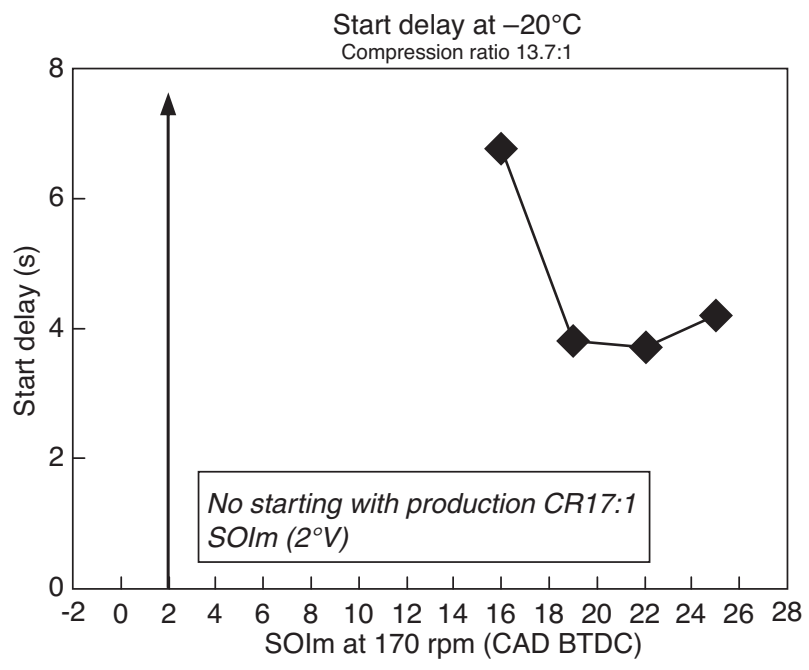

Figure 17

Effect of start of main injection (SOIm) on the start ability. The values of SOIm are represented at $170 \mathrm{rpm}$ breakpoint $\left(\right.$ Qtot $=100 \mathrm{~mm}^{3} /$ cycle; RailP $=30 \mathrm{MPa}$; Qpil = $15 \mathrm{~mm}^{3} / \mathrm{str}$; relative $\mathrm{SOIp}=5 \mathrm{CAD}$ at $170 \mathrm{rpm})$.

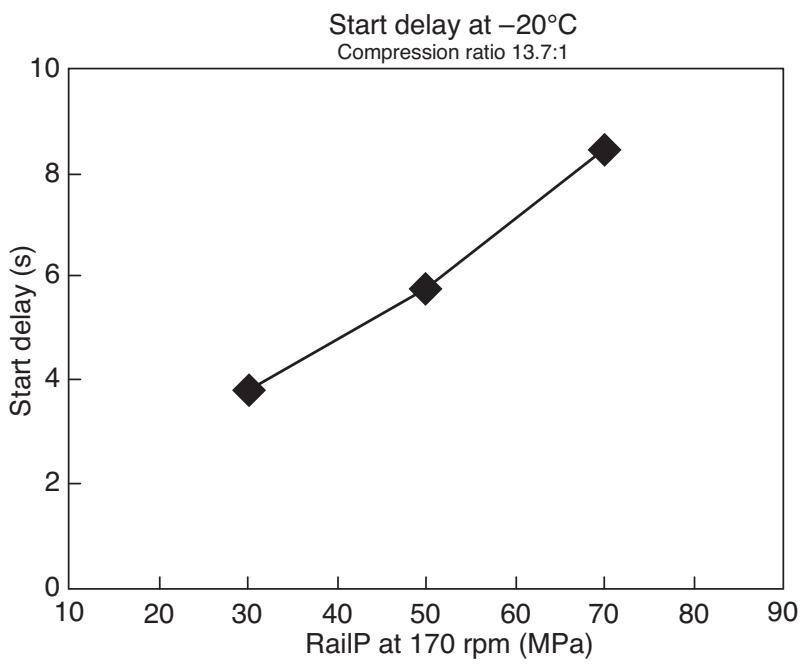

Figure 18

Effect of rail pressure (RailP) on the start ability. The values of RailP are represented at $170 \mathrm{rpm}$ breakpoint, and are constant for the whole engine speed operating range during starting $\left(\mathrm{Q}\right.$ tot $=100 \mathrm{~mm}^{3} /$ cycle; SOIm $=19 \mathrm{CAD}$ BTDC ; Qpil $=15 \mathrm{~mm}^{3} / \mathrm{str} ;$ relative SOIp $=5$ CAD at $\left.170 \mathrm{rpm}\right)$.
For these tests, the best starting results are obtained with an injection timing early in the compression stroke (SOIm $=$ $19-22^{\circ} \mathrm{CA}$ ), so almost $20^{\circ} \mathrm{CA}$ earlier than the nominal setting $\left(\mathrm{SOIm}=3^{\circ} \mathrm{CA}\right)$. This optimization results from two opposite trends regarding injection timing:

- on the first hand, early timing is necessary when using the low compression ratio engine in order to get more time for vaporization;

- on the other hand, if injection occurs too early, in-cylinder temperature is too low, which is not favorable to the vaporization process and increases the risk of wall wetting.

The need for increasing vaporization duration is discussed in more detail below, with CFD calculations and cylinder pressure analysis.

\subsubsection{Rail Pressure}

An increase in rail pressure during the cranking operation may influence starting capability for three main reasons:

- first, it can help to vaporize injected fuel, by reducing fuel droplet size and by increasing the air entrainment into the spray;

- second, kinetic energy of the spray is higher when injection pressure is increasing. This phenomenon may enhance cylinder liner wetting, if injection occurs when the piston is down enough [15]. Considering later injection timing (close to the TDC), a large quantity of fuel reaches the piston wall and the higher kinetic energy may help to guide fuel towards the glow plug; this effect may appear depending on piston bowl shape, injection timing, etc.;

- third, it tends to increase the Friction Mean Effective Pressure (FMEP) due to the entrainment torque of the fuel pump. So energy necessary to enable engine auto-running has to be higher, which is a penalty for start delay.

The influence of rail pressure is studied by variations in the setpoint, from 30 up to $70 \mathrm{MPa}$. It can be noticed that the ability of the injection system to reach the setpoint during cranking operation is obtained for a rail pressure equal to $20 \mathrm{MPa} / \mathrm{s}$. That has to be included in start delay. Settings are maintained constant between 150 and $1000 \mathrm{rpm}$, as in the nominal configuration with compression ratio 17:1. The results of the effect of injection pressure variation on start delay are displayed in Figure 18.

Start delay increases with the injection pressure, from $4 \mathrm{~s}$ to $8 \mathrm{~s}$ when adding $40 \mathrm{MPa}$. This result is probably a tradeoff between the aspects mentioned above. The increase in injection pressure induces damage of the start ability of the engine.

\subsubsection{Pilot Injection}

In Figure 19, showing the evolution of start delay with the SOIp; timing of the pilot injection (Start Of Injection) is given according to the timing of the main injection. 


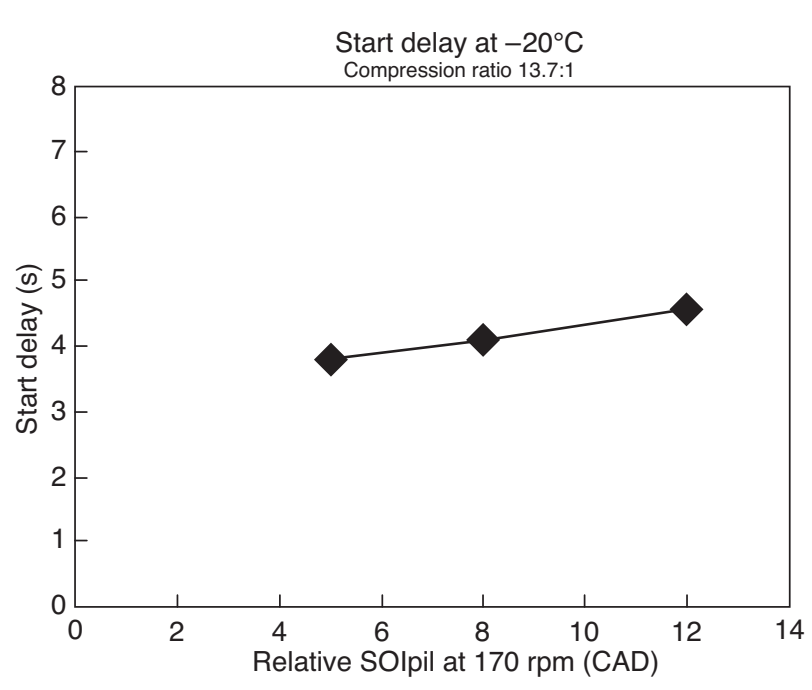

Figure 19

Effect of start of pilot injection (relative to main injection) on the start ability. The values of relative SOIpil are represented at $170 \mathrm{rpm}$ breakpoint $\left(\right.$ Qtot $=100 \mathrm{~mm}^{3} /$ cycle; RailP = $30 \mathrm{MPa}$; Qpil $=15 \mathrm{~mm}^{3} / \mathrm{str} ; \mathrm{SOIm}=19 \mathrm{CAD}$ BTDC at $170 \mathrm{rpm}$ ).

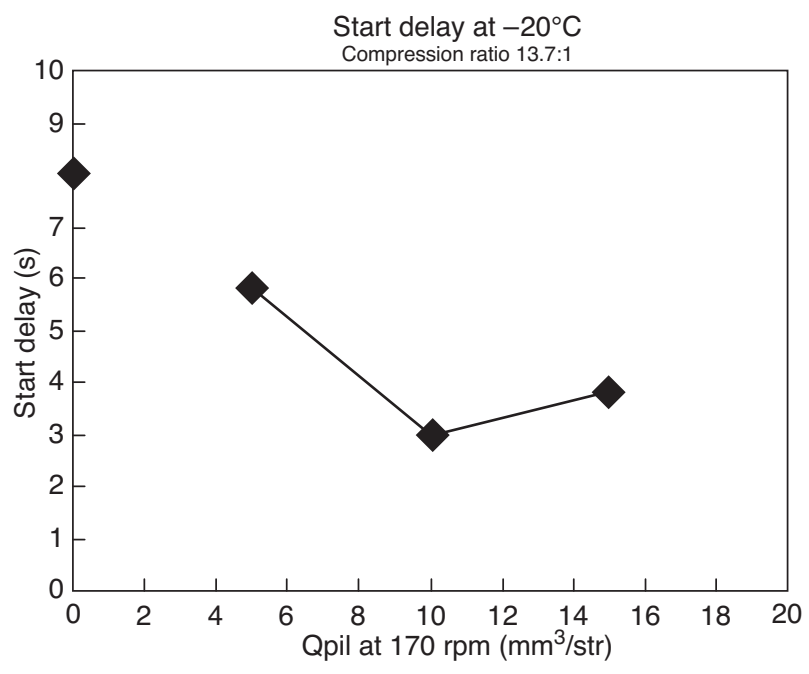

Figure 20

Effect of fuel quantity in pilot injection (Qpil) on the start ability. The values of Qpil are represented at $170 \mathrm{rpm}$ breakpoint $\left(\right.$ Qtot $=100 \mathrm{~mm}^{3} /$ cycle; RailP $=30 \mathrm{MPa} ;$ SOIm = 19 CAD BTDC; relative SOIp $=5$ CAD at $170 \mathrm{rpm}$ ).
It can be noticed that the earlier the pilot injection, the worse the start delay. The decrease in temperature in the combustion chamber is probably penalizing vaporization of the pilot injection, and enhancing wall wettings.

Pilot injection quantity was varied (Fig. 20) with a constant total quantity injected into the chamber, e.g. the higher the pilot injection quantity, the lower the main injection quantity.

The best setting of pilot quantity seems to be around $9 \mathrm{~mm}^{3} / \mathrm{str}$; this result has to be considered carefully, because of the difficulty of controlling low injection quantity in such conditions (see Fig. 2). Moreover, this behavior depends on temperature tests, and is specific to the engine combustion system design. In the present case, regarding the cylinder pressure signal, the vaporization of the pilot injection (if it is effective) is too low to induce a drop in in-cylinder pressure and, on the other hand, no fuel from the pilot injection seems to burn before the main injection. As a consequence, no potential heat release coming from the combustion of the pilot injection could make the combustion of the main injection easier (with the help of ignition delay reduction, HLC increase, etc.). As well as the beneficial effect of injection splitting, the pilot injection may generate a small spray penetration (low injection duration), and consequently a small wall wetting effect. The pilot injection seems to give an available quantity of fuel that is favorable to the combustion of the main injection and to the start ability of the engine. This is confirmed by the fact that cancelling the pilot injection induces an increase in start delay. This last effect tends to be less significant at very low temperatures $\left(T^{\circ}<-20^{\circ} \mathrm{C}\right)$.

\subsubsection{Total Injected Quantity}

Total injected quantity was estimated for cold start capability, in a range from 80 to $112 \mathrm{~mm}^{3} /$ cycle. It may be recalled that the quantity setpoint for the starting phase with the nominal $\mathrm{CR}$ is $100 \mathrm{~mm}^{3} /$ cycle, which is quite a high value. All the tests were done with the same value of pilot injection quantity; in fact, only the main injection quantity or duration are changed in the present tests.

Injection quantity increase is supposed to give a benefit for many reasons:

- it may increase the quantity of evaporated fuel and, as a consequence, may increase the probability of meeting between fuel vapor and glow plug, and consequently autoignition opportunities;

- in the case of auto-ignition, it may increase heat release, and consequently enhance a quick engine speed rise, which will improve the start ability.

On the other hand, an excess of fuel quantity may have some drawbacks:

- overcooling the charge because of fuel vaporization, involving temperature drop and penalty for auto-ignition;

- excess of wall wetting, and consequently smoke emissions and excessive fuel consumption, lubricant dilution risk, etc. 


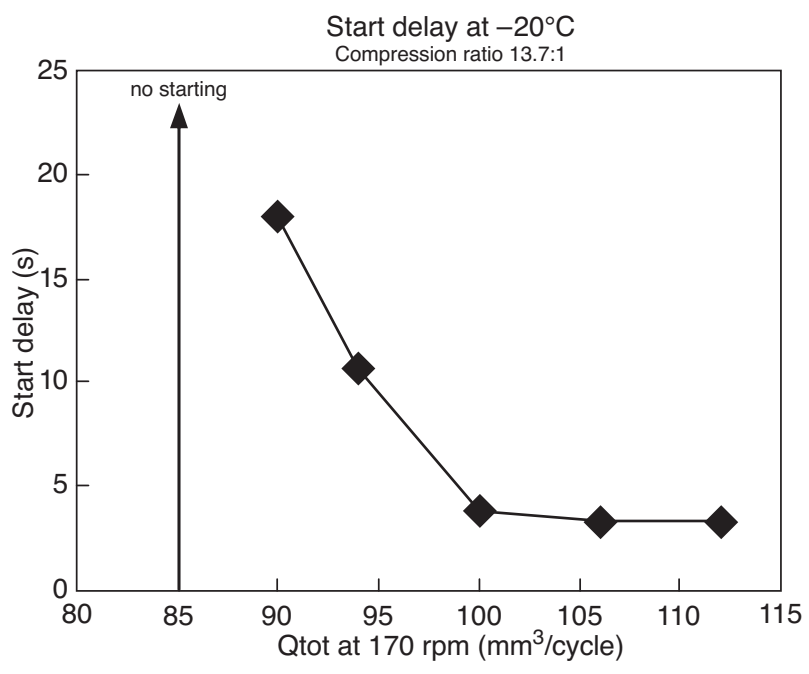

Figure 21

Effect of total fuel quantity (Qtot) on the start ability. The values of Qtot are represented at $170 \mathrm{rpm}$ breakpoint (SOIm $=19$ CAD BTDC; RailP = $30 \mathrm{MPa} ;$ Qpil $=15 \mathrm{~mm}^{3} / \mathrm{str}$; relative SOIp $=5$ CAD at $170 \mathrm{rpm})$.

The results are shown in Figure 21.

Increasing fuel injection is always positive for start delay, until fuel quantity is equal to $100 \mathrm{~mm}^{3} /$ cycle. Beyond this value, no significant benefit is obtained, but nevertheless, start delay is not damaged. On the contrary, by decreasing fuel quantity, starting occurs later and later, until no starting below $85 \mathrm{~mm}^{3} /$ cycle.

\subsection{Start Delay Potentialities at Low Compression Ratio for Various Temperatures}

Similar injection setting optimizations were operated at the low compression ratio, 13.7:1, for temperatures between $20^{\circ} \mathrm{C}$ and $-25^{\circ} \mathrm{C}$. The results obtained are compared in Figure 22 with reference settings for the nominal compression ratio 17:1. Other settings (in particular, starter rpm and preglowing duration) are kept constant for the two configurations, as mentioned in Table 2.

Thus, with a low CR, it is possible to reach a similar start delay to with nominal $\mathrm{CR}$, even at very low temperatures. This issue depends on modifying injection settings (Fig. 23) according to global trends such as:

- an earlier injection timing (from $+3 \mathrm{CAD}$ to $+17 \mathrm{CAD}$ ). This recalibration is due to the increase in the time needed to vaporize and ignite the charge;

- an increase in fuel quantity which enhances the first autoignition, and consequently the engine start;

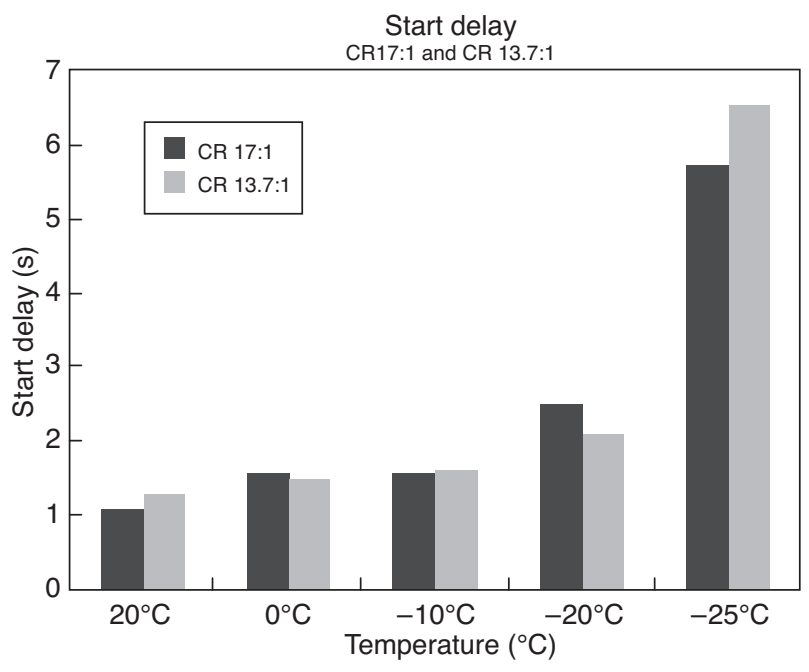

Figure 22

Start delay according to temperature with CR 17:1 (nominal injection settings) and CR 13.7:1 (optimized injection settings).
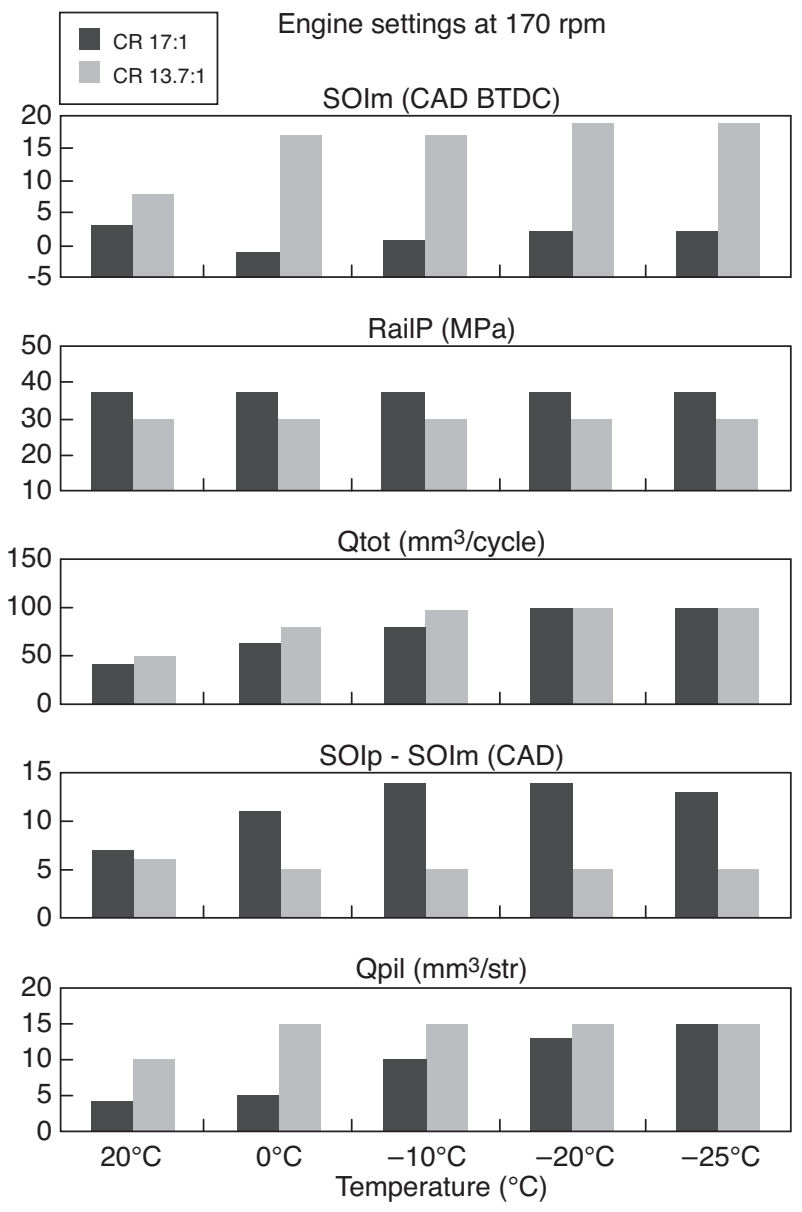

Figure 23

Optimal settings at $170 \mathrm{rpm}$ for the CR 13.7 application, compared with production engine settings (CR 17:1). 
- a lower or an equivalent injection pressure, in order to reduce FMEP of the high-pressure pump as much as possible. This aspect seems to be more important than potential benefits in vaporization and combustion aspects;

- pilot injection settings are firstly a function of engine applications; for the present engine, reducing pilot injection dwell seems to bring benefits.

Of course, other criteria than start delay have to be taken into account for the calibration of a starting phase, such as smoke or HC emissions. Nevertheless, reducing start delay allows one to limit engine cycles without combustion during cranking, and consequently promotes limitations of $\mathrm{HC}$ emissions and smoke. Thus, the start delay criterion is a key factor for calibration. For close values of start delay, settings limiting emissions will be preferred; for example, by limiting total injection quantity as much as possible.

\subsection{Analysis of Engine Cycles During Starting Operation}

\section{Cylinder Pressure Analysis}

As described before, measurements of the cylinder pressure were performed on each cylinder during starting operations. In the first compression and combustion cycles during the engine cranking, these measurements are affected by thermal phenomena which alter the accuracy of the signal:

- thermal shocks applied to the sensor diaphragm, which are caused by contact with very hot gas combustion for a short time during the engine cycle;

- long-term thermal drift, which is the consequence of the sensor body heating for a few seconds of the starting operation. This phenomenon implies a cycle-to-cycle drift, that can be corrected by data post-processing, including a very simple correction for each cycle. However, it is likely as corrected cylinder pressures will not represent exactly the real physical ones, which can have an impact on IMEP calculations and on combustion analysis.

The first cycles during the starting operation with CR 17:1 and CR 13.7:1 configurations at $-20^{\circ} \mathrm{C}$ are described below. Injection settings at $170 \mathrm{rpm}$ for both configurations are equal to those mentioned in Figure 23 for the same temperature.

The first cycles with CR 17:1 are illustrated for one cylinder in Figure 24. Maximum in-cylinder pressures during compression are estimated at between $2.8 \mathrm{MPa}$ (first cylinder pressure with a complete intake cycle, engine speed $=170 \mathrm{rpm}$ ) and $3.4 \mathrm{MPa}$ (sixth cycle and following cycles, engine speed $\sim 1000 \mathrm{rpm}$ ). Blow-by and air filling explain this cylinder pressure evolution, as they are notably related to engine speed. From a combustion point of view, we notice that combustion of cycle 3 is the most energetic one on this cylinder, with a pressure peak of around $10 \mathrm{MPa}$. IMEP on this cycle is around $1 \mathrm{MPa}$. In addition, pressure

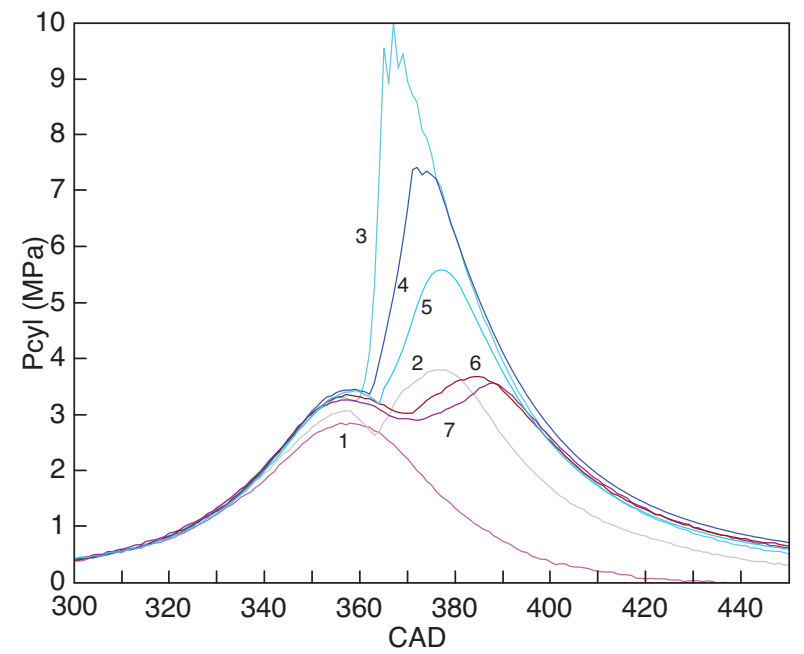

Figure 24

Cylinder pressure for the first 7 cycles during starting operation-CR 17:1 - nominal injection settings.

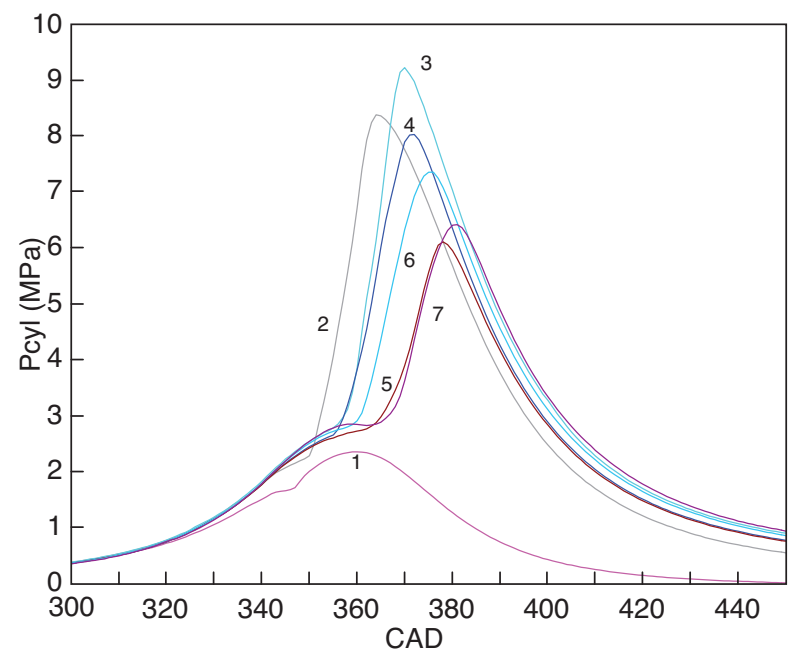

Figure 25

Cylinder pressure for the first 7 cycles during starting operation - CR 13.7:1 - optimized injection settings.

drop due to fuel vaporization is perceptible in the first cycles, such as cycle 2 .

The first cycles with CR 13.7:1 on one cylinder with optimized injection settings are introduced in Figure 25. In this configuration, maximum in-cylinder pressure during compression stroke is from $2.5 \mathrm{MPa}$ (first cycle, at $170 \mathrm{rpm}$, including a pressure drop due to vaporization) to $3 \mathrm{MPa}$ (idle speed, $1000 \mathrm{rpm})$. It can be noticed that:

- the combustion timing of the first combustion (cycle 2 in CR 17:1; cycle 3 in CR 13.7:1) is equivalent or earlier in CR 13.7:1, which is partially explained by the earlier SOI adopted in such conditions; 
- combustion is more efficient for cycle 4 and the following cycles in CR 13.7:1, in comparison with CR 17:1. These cycles correspond to the end of the starting phase and the beginning of idle speed. This is explained by the fact that, at this moment and for CR 13.7:1, the charge tends to stop burning on several cylinders. Consequently, combustion in firing cylinders (like the one illustrated here) has to assume a higher load to keep the engine speed constant (and, moreover, injected fuel quantity is higher, due to idle speed regulation).

The time necessary to burn $3 \mathrm{mg}$ of fuel is estimated from the injection timing of the pilot and main, for both engine configurations, and for the cycle 2 and cycle 3 (at engine speed close to $170 \mathrm{rpm}$ ). This first estimation of the time needed for the air-fuel mixing preparation and auto-ignition delay is illustrated in Figure 26. As can be noticed, this duration is longer for CR $13.7: 1$, which partly explains why injection timing has to be earlier in this last case.

In order to explain phenomena such as vaporization, airfuel mixture and auto-ignition at low compression ratio, several computations were performed using the CFD code IFP-C3D described above.

\section{RESULTS OF CFD COMPUTATIONS}

The aim is to give indications of the sensitivity of cold start to several engine variations observed during experiments.

In the present cold start conditions, computations show that there is a strong interaction between the spray and the piston walls. Indeed, calculations show that the major part of the total injected fuel (Qtot $=100 \mathrm{~mm}^{3} /$ cycle) forms a liquid

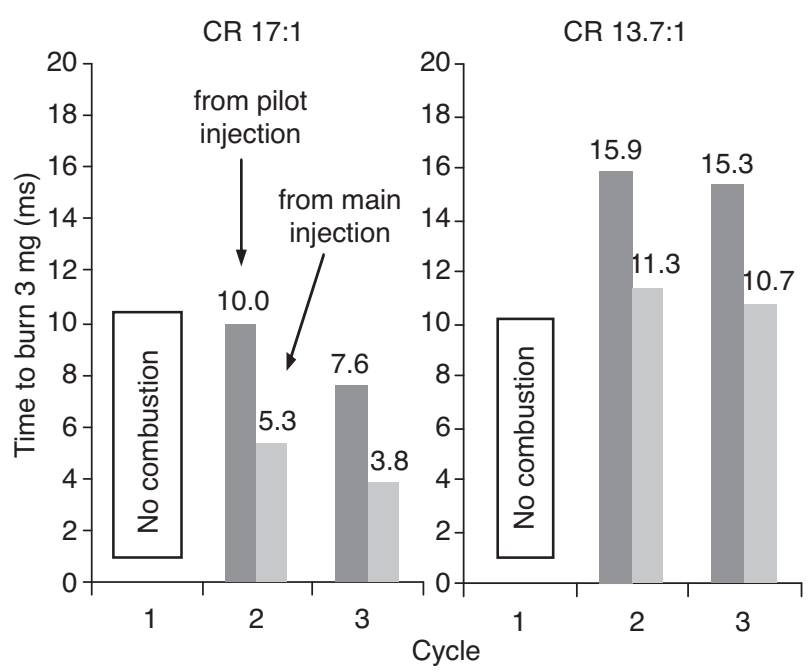

Figure 26

Time necessary to burn $3 \mathrm{mg}$, from pilot injection timing (SOIp) and main injection timing (SOIm). Temperature: $-20^{\circ} \mathrm{C}$.

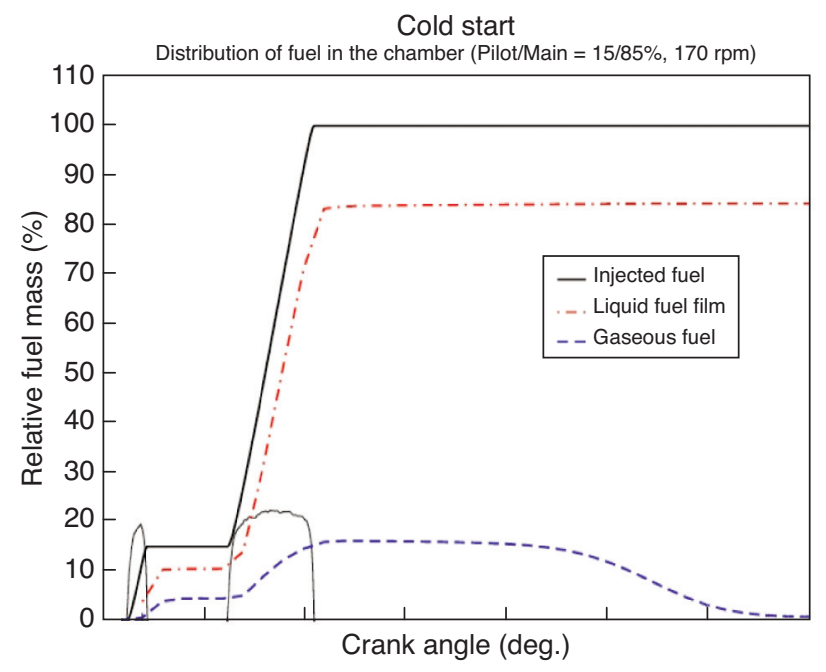

Figure 27

Distribution of fuel in the chamber.

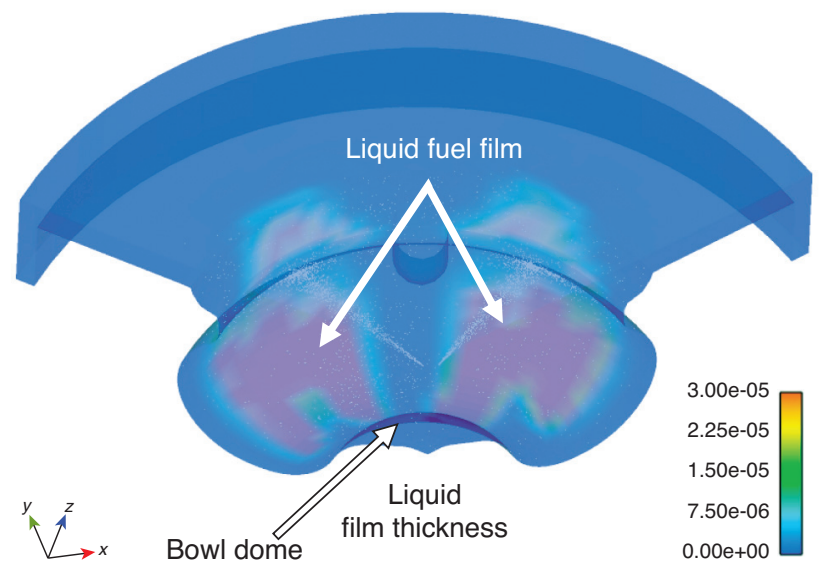

Figure 28

Liquid film thickness on bowl walls computed at the end of main injection.

film on the walls of the bowl. In fact, only about $15 \%$ of the injected fuel is evaporated. Moreover, as the piston wall temperature is very low, the fuel is trapped in the liquid film (the evaporation of this is mainly governed by the heat exchange with the wall) and will not be available for an eventual combustion during the present first engine cycle. Only $15 \%$ of fuel vapor can be involved in this combustion. Figure 27 shows the evolution of the fuel mass distribution between liquid film and vapor during injection and the beginning of combustion.

In Figure 28 compared with Figure 14, it can be observed that the wetted areas observed on the bowl walls in the experimental engine are very similar to those computed. 
Moreover, the heat used for fuel vaporization is taken directly from the surrounding air. As a consequence, the fuel vaporization induces a global cooling of the gas in the combustion chamber. This cooling can be observed in the chamber temperature evolution (see Fig. 29), but also on the mean in-cylinder pressure evolution (see Fig. 30). Indeed, the cooling induces a decrease in the mean in-cylinder pressure during the injection. This pressure loss can be observed in the experimental in-cylinder evolution too. The fact that the computed pressure decrease is very comparable with the experimental one (see Fig. 30) shows that the evaporated fuel mass may be well predicted by the model, and thus global prediction of vaporization and mixture phenomena may be consistent.

Looking at the 3D physical data fields in the combustion chamber allows one to observe that the vaporization process is very low in the area near the injector nozzle. Here, in the present conditions, the sprays are very concentrated and the air entrainment by the fuel sprays is quasi-null. In fact, it can be observed that the fuel is vaporized in the areas of spray/wall interaction. Indeed, after the impact the droplets resulting from the spray/wall or spray/film interaction are smaller and more scattered. As a consequence, in those areas of spray/wall or spray/film interaction, where the main part of fuel evaporation takes place, there is a loss of temperature due to the local vaporization of the fuel (the heat needed for vaporization is taken directly from local surrounding gases). Thus, the gaseous fuel "clouds" correspond to cold areas (see Fig. 31, Fig. 34 and Fig. 35). In fact, a segregation can be noticed between areas with gaseous fuel and areas with "high" temperature. This first indication can partly explain the difficulties of starting a Diesel engine with reduced compression ratio in such cold conditions.

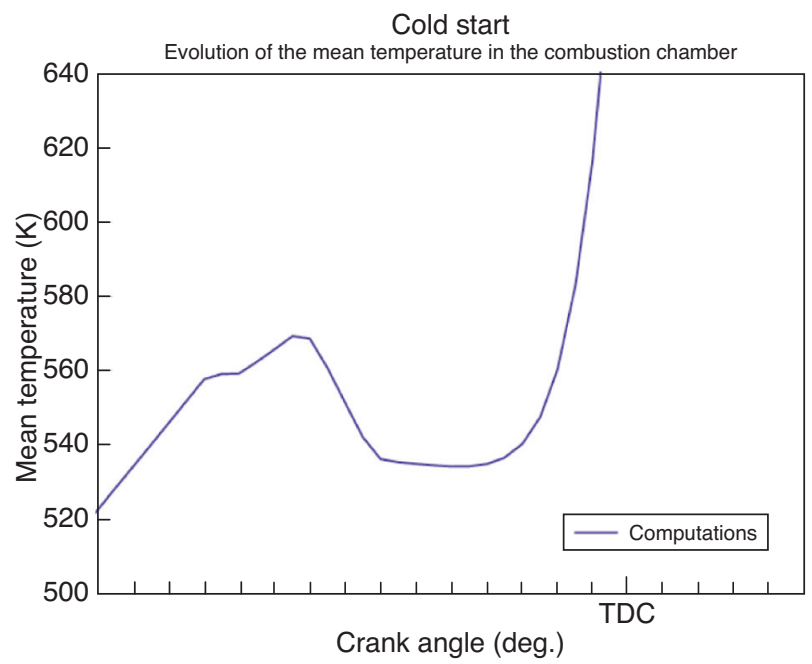

Figure 29

Mean Temperature evolution in the chamber.

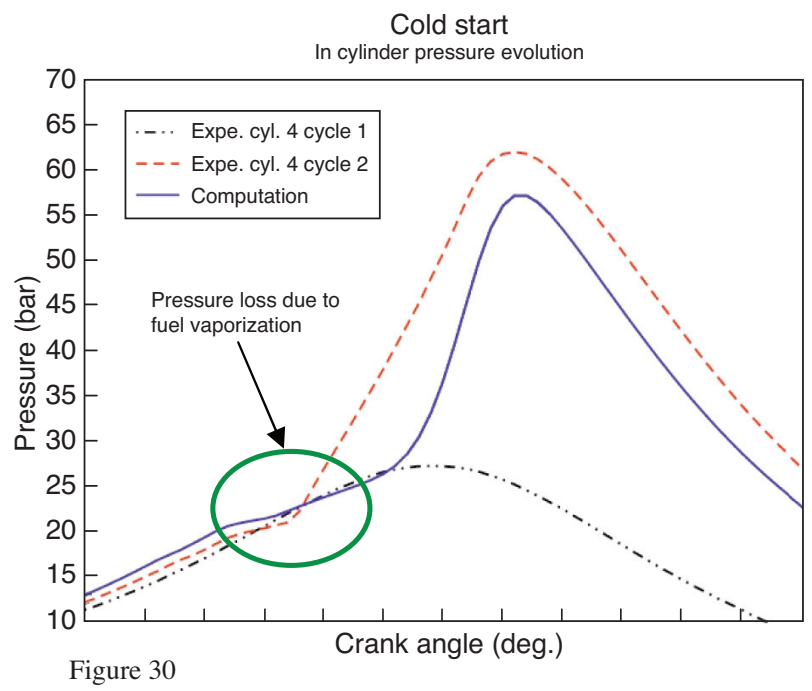

Mean pressure evolution in the chamber.

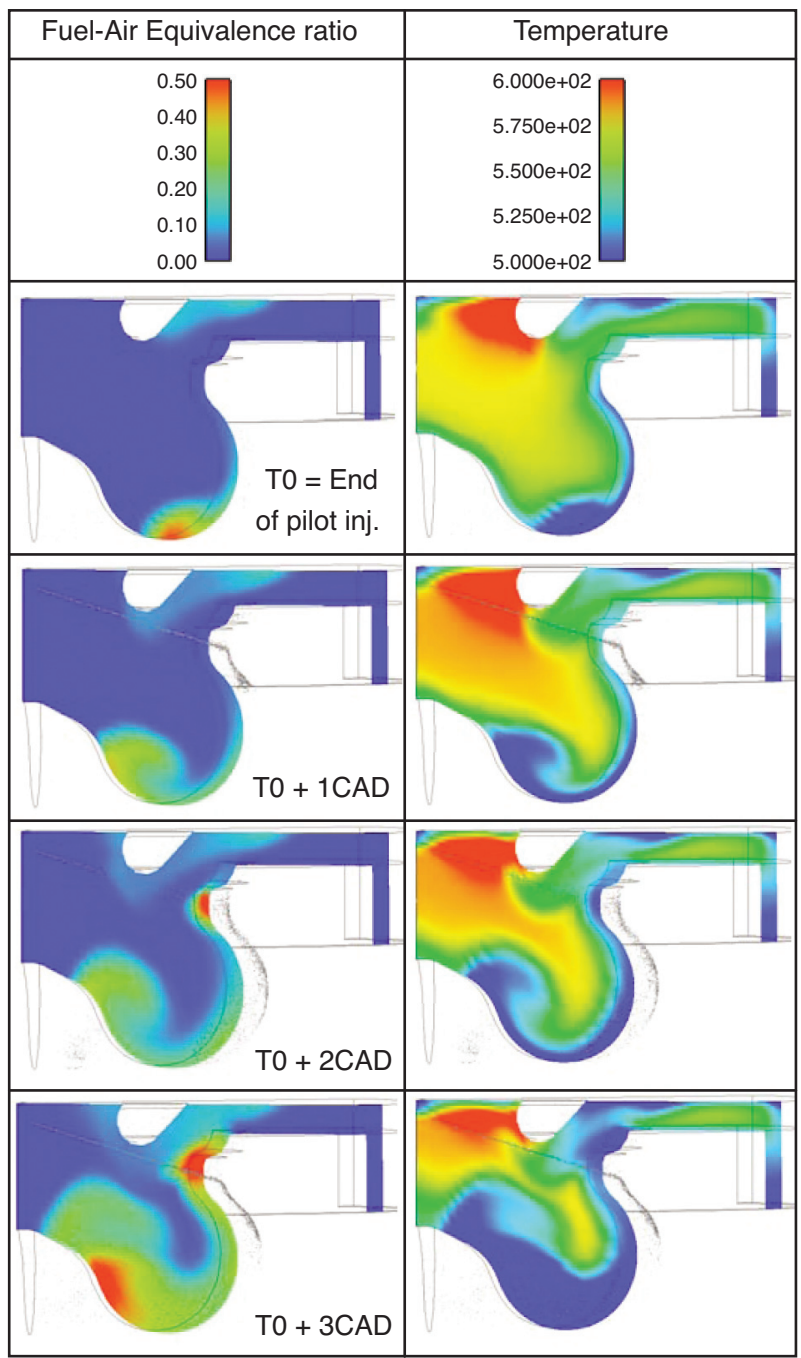

Figure 31

Evolution of the fuel-air equivalence ratio and temperature in combustion chamber. 


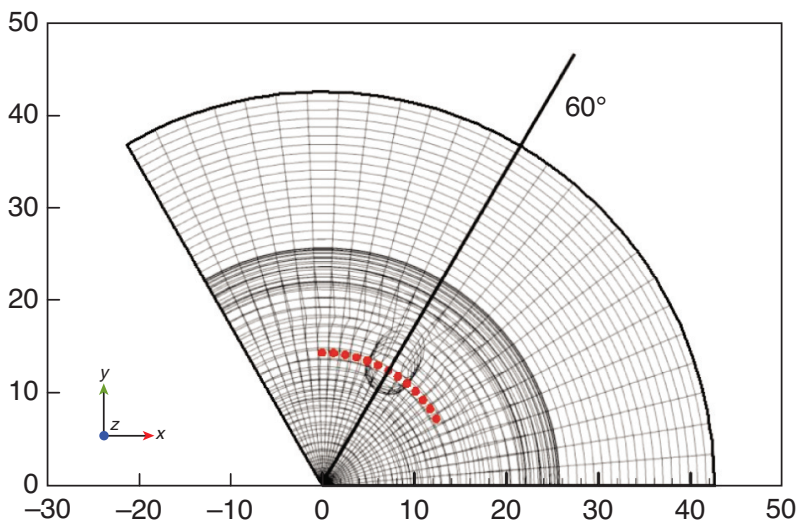

Figure 32

Location of observation points in the computational domain.

\section{Cold start, engine DW10-ATED4}

Local evolution of temperature $(R=14.3 \mathrm{~mm}, Z=5 \mathrm{~mm})$

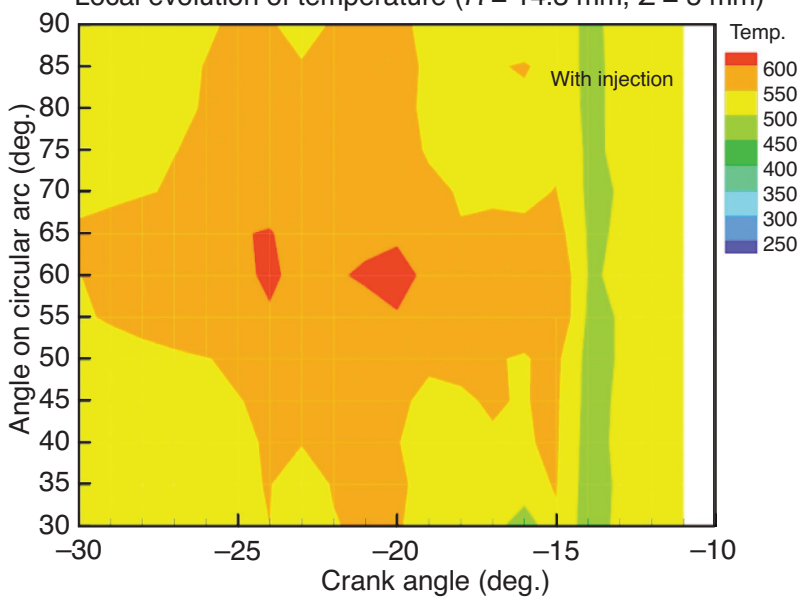

Figure 33

Map of temperature just under glow plug.

Moreover, these non-zero fuel-air equivalence ratio "clouds" possess a small momentum which results from the transfer from the spray momentum to the ambient gas. This small velocity allows them to move towards the glow plug (this spatial evolution can be observed in Fig. 31).

In order to measure the influence of the glow plug on local temperature, numerical probes were placed in the computational domain $5 \mathrm{~mm}$ below the cylinder head surface (just under the lower point of the plug) and on a circle of radius equal to $14.3 \mathrm{~mm}$ every 5 degrees from 30 to $90^{\circ}$, as shown in Figure 32. Those points allow one to obtain a map of temperature on the circular arc function of crank angle. Figure 33 allows one to confirm that the glow plug (here located just above the probes between $50^{\circ}$ and $70^{\circ}$ on the circular arc) induces a local heating of the gases. Thus, the plug vicinity is, in cold start conditions, the only place where the needed conditions in terms of temperature can be obtained. The evolution of the gaseous fuel areas have to be well synchronized in the engine cycle in order to obtain the conditions needed for auto-ignition and then combustion.

Finally, in the given conditions of cold starts, some initial and boundary temperatures were increased. This induces an increase in mean in-cylinder temperature around the Top Dead Center of temperature. These modifications can be justified by the differences between experiments and the numerical model:

- the first experimental engine cycle with combustion is, in reality, at least the second engine cycle during cranking. During the first cycle the wall temperatures may have increased;

- the fuel temperature may increase due to pressure effects in the rail. Moreover, the experimental fuel possesses a slightly different distillation curve compared with that of the model mono-component fuel, which needs a higher heating for evaporation;

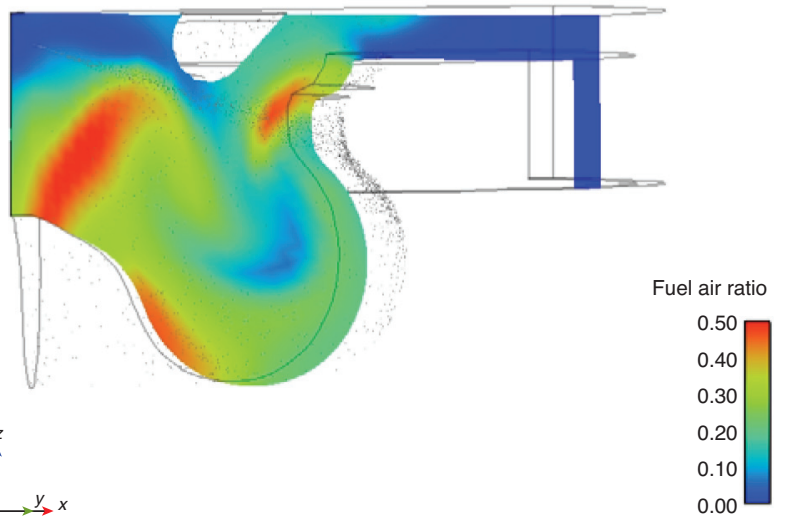

Figure 34

Fuel-air ratio in the chamber at the end of main injection.

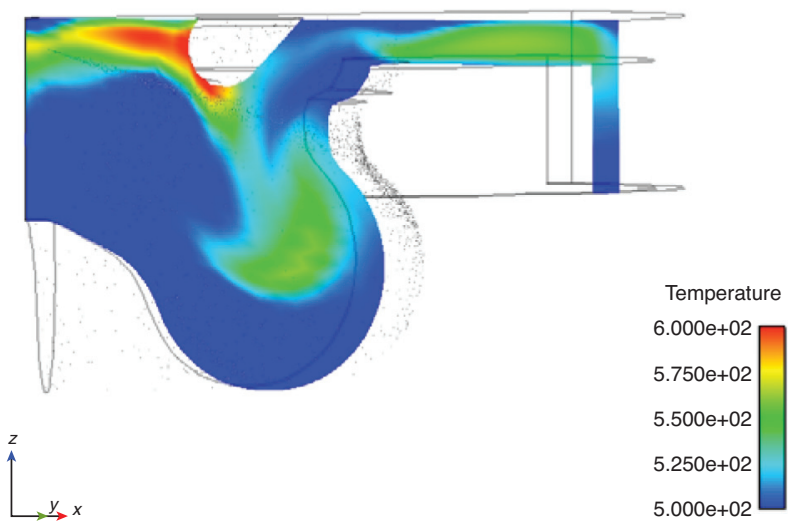

Figure 35

Temperature in the chamber at the end of main injection. 
- in the present model, the computations start at the bottom dead center just before the first injection. The preglowing time is not taken into account and may have induced a small increase in in-cylinder temperature and cylinder head walls near the plug.

- the way of modeling the blow-by phenomenon (see Fig. 3) induces an increase in heat losses. Indeed, the wall surface is increased by $29 \%$ at the TDC, and as a consequence the in-cylinder temperature may be underestimated around the TDC.

Increasing some initial and boundary temperatures in order to model the first engine cycle with combustion allows one to obtain an auto-ignition (cool flame) which starts $2 \mathrm{CAD}$ after the beginning of the main injection, followed by a main combustion $10 \mathrm{CAD}$ after. This combustion burns the whole gaseous fuel mass available (about $15 \%$ of the injected mass), and it induces an in-cylinder pressure evolution comparable with the experimental second engine cycle one (see Fig. 30). It should be noted that the experimental autoignition occurs almost $3 \mathrm{CAD}$ after the end of the main injection. This delay allows one to assume that this combustion does not concern the fuel directly available in the spray, but the vapor provided by the vaporization process taking place in the bowl near the spray/wall interaction areas, as observed in the computation results.

This observation shows that the computation tends to be well representative (liquid film, fuel evaporation and combustion) of reality.

So these calculations may show that, in this engine, vaporization and mixture preparation are performed by a process involving: first, impact on the wall; second, vaporization along the wall from the re-entrant to the bottom of the tore; third, vapor "clouds" moving towards the glow plug; finally, auto-ignition at the glow plug. This process is contrary to the common process, e.g. auto-ignition at the glow plug directly in the fuel spray.

It is important to specify that, in this calculation, the autoignition with cool flame occurs on only one mesh cell of the computational domain in the direct vicinity of the glow plug. The uncertainty of the combustion observed experimentally seems to exist in the computations as well. Moreover, viewing this uncertainty of the computed auto-ignition, and in order to improve the computation accuracy, a study on the sensitivity to the mesh size may be performed in future work.

Moreover, this observation confirms the fact that in such conditions (cold start) the phenomena are extremely local. Thus, the assumptions for a computational model may be well adapted to such a configuration.

It should be noted that the use of a multi-component fuel model would have been better adapted for the present study, as the behavior of "light" and "heavy" components may be very different, mainly in terms of evaporation in such low temperature conditions; but the liquid-film model (which must be used in cold start conditions) has not yet been adapted to take into account multi-component fuels.

In order to improve the numerical model realism according to the experiments, the way of representing the blow-by phenomenon, which is very important in such cold start conditions, always has to be modified. In the present study, only a loss of compression ratio is modeled with an increase in combustion chamber volume. But the air located in this extra volume is heated like the rest of the charge. This contributes to underestimating the mean in-cylinder temperature around the TDC (during injection) and the increase in heat losses due to the wall of the extra volume.

\section{WAYS TO IMPROVE COLD START OPERATION}

In this part of the paper various ways of impacting the start ability of a low CR Diesel engine in cold ambient conditions are described $[13,16]$ :

- preglowing duration (and subsequently glow plug temperature);

- Nozzle Tip Protrusion (NTP);

- injector spray orientation;

- injector spray angle;

- cranking speed.

\subsection{Influence of Preglowing Duration on Start Ability}

As mentioned before, the engine is equipped with selfregulated metal glow plugs. In cold conditions during the first engine cycles, at the end of the compression stroke, the

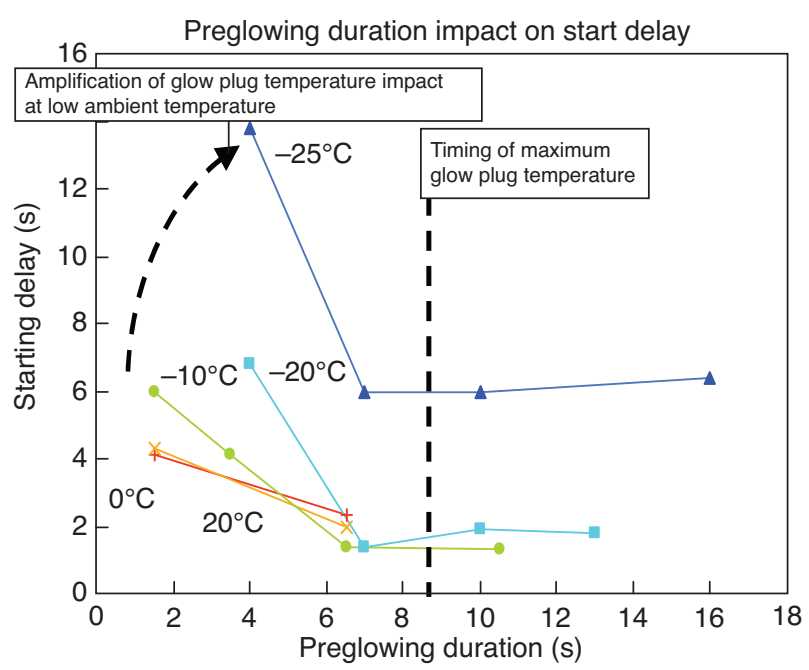

Figure 36

Impact of preglowing duration on start delay, for ambient temperatures from $625^{\circ} \mathrm{C}$ to $20^{\circ} \mathrm{C}-\mathrm{CR}=13.7: 1$. 


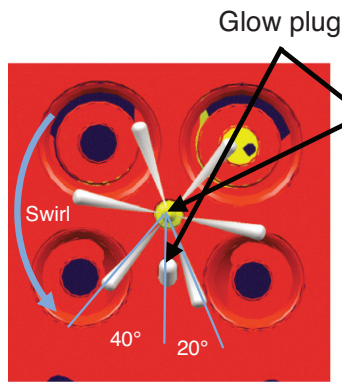

View from bottom
View in profile

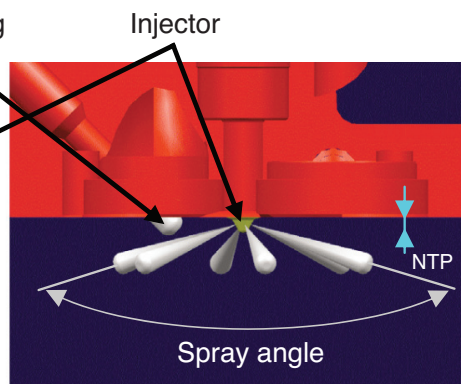

Figure 37

Relative position of glow plug $v s$. injector.

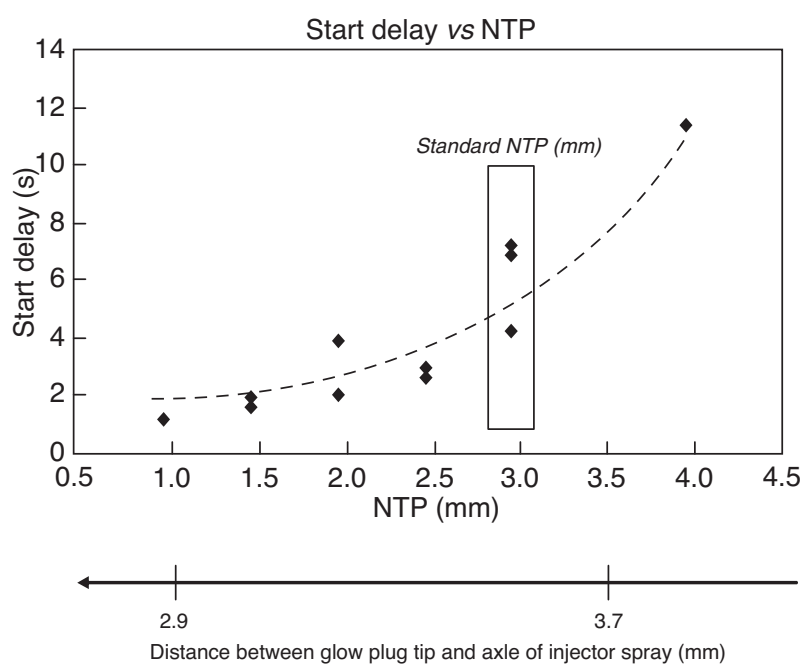

Figure 38

Impact of injector NTP on start delay at $-20^{\circ} \mathrm{C}$.

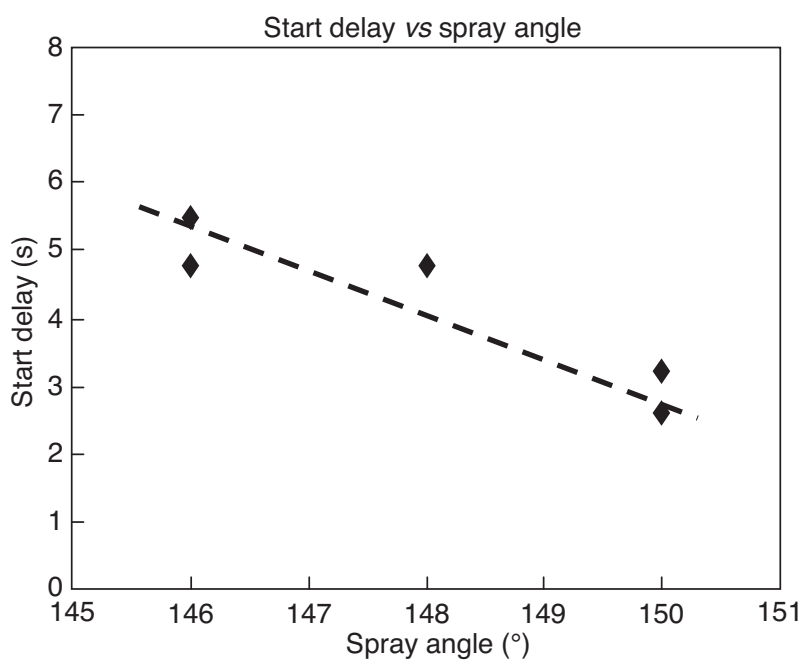

Figure 39

Impact of injector spray angle on start delay at $-20^{\circ} \mathrm{C}$ (static hydraulic flow: $333 \mathrm{~cm}^{3} / 30 \mathrm{~s} / 10 \mathrm{MPa}$ ). temperature is not sufficient for self-ignition and the fuel-air mixture ignites due to the calories provided by the glow plug. This is checked on the engine by an impossibility of starting without glow plug heating with ambient temperature below $0^{\circ} \mathrm{C}$. Moreover, engine start capability is first governed by the temperature level of the glow plug, as can be seen in Figure 36.

For preglowing duration shorter than $8-9 \mathrm{~s}$, the longer the preheating duration, the shorter the start delay. This trend is all the more obvious when temperature is low. As the temperature of the glow plug tip is directly correlated with heating duration, it can be concluded that a high temperature glow plug is specially required for very low temperature in low CR applications. In addition, due to consumer requirements, this high temperature has to be reached in a very short time.

Therefore, glow plug temperature increase can facilitate engine starting and reduce start delay with low compression ratio.

\subsection{Impact of Injector Nozzle Tip Protrusion and Injector Spray Angle}

The impact of Injector Nozzle Tip Protrusion (NTP) illustrated in Figure 37 was studied by varying the thickness of spacer rings located below the injectors.

From a standard position, NTP $=3 \mathrm{~mm}$, the injector was driven inside the chamber (NTP $=4 \mathrm{~mm}$ ) or inversely removed from the chamber $(\mathrm{NTP}=1 \mathrm{~mm})$. Figure 38 shows that start delay decreases when NTP decreases. In fact, this induces the reduction of the distance between the tip of the glow plug and the axis of the injector spray.

In order to study the impact of the injector spray angle, we used injector nozzles with reduced spray angle.

We observe (Fig. 39) that start delay decreases when spray angle increases, which allows the spray to go up in the chamber and so near the glow plug, as for the NTP reduction presented before.

\subsection{Impact of Injector Spray Orientation}

From the standard definition illustrated before, the injection orientation was varied in the two directions: $+/-20^{\circ}$.

Whatever the direction of the rotation (Fig. 40), the start delay is reduced in quite the same way (Fig 41).

Taking into account that the distance between the glow plug tip and the axis of the injector is only reduced with $-20^{\circ}$ rotation, the result obtained with $+20^{\circ}$ is surprising. That would mean that the impact of the swirl is not negligible at such a low engine speed (180 rpm) and thus it allows reducing start delay. 


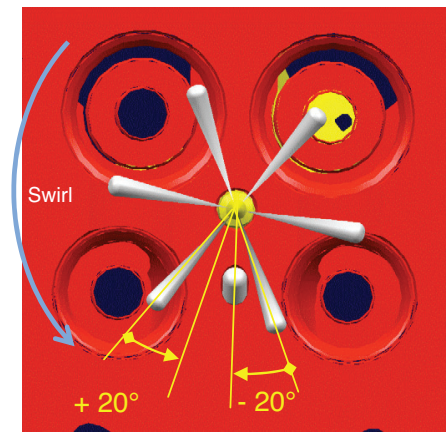

Figure 40

Modification of injector orientation.
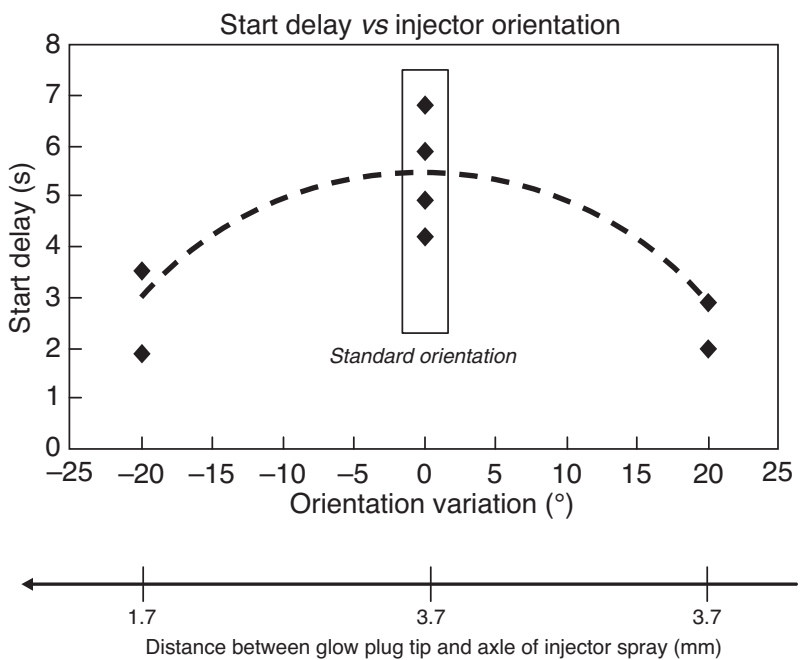

Figure 41

Impact of injector orientation on start delay at $-20^{\circ} \mathrm{C}$.

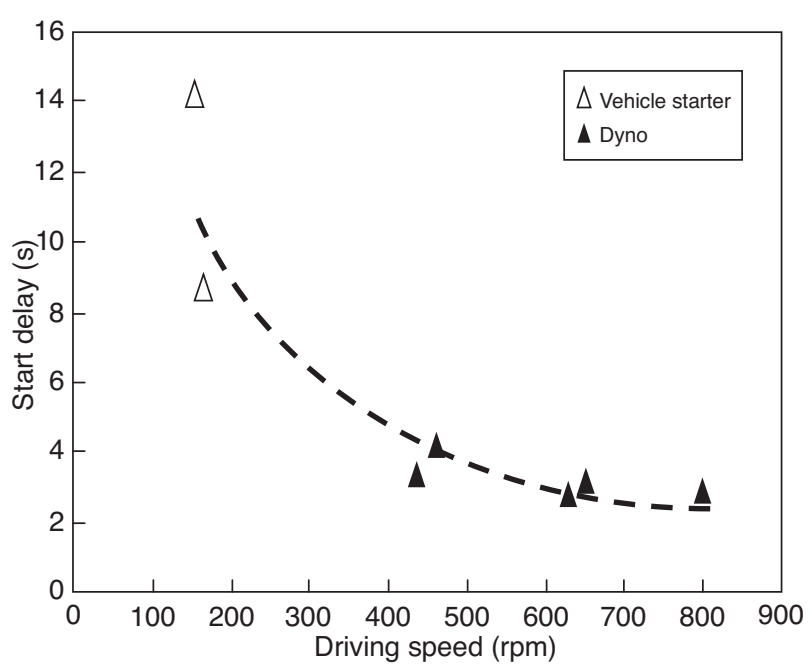

Figure 42

Impact of cranking speed on start delay at $-25^{\circ} \mathrm{C}$.

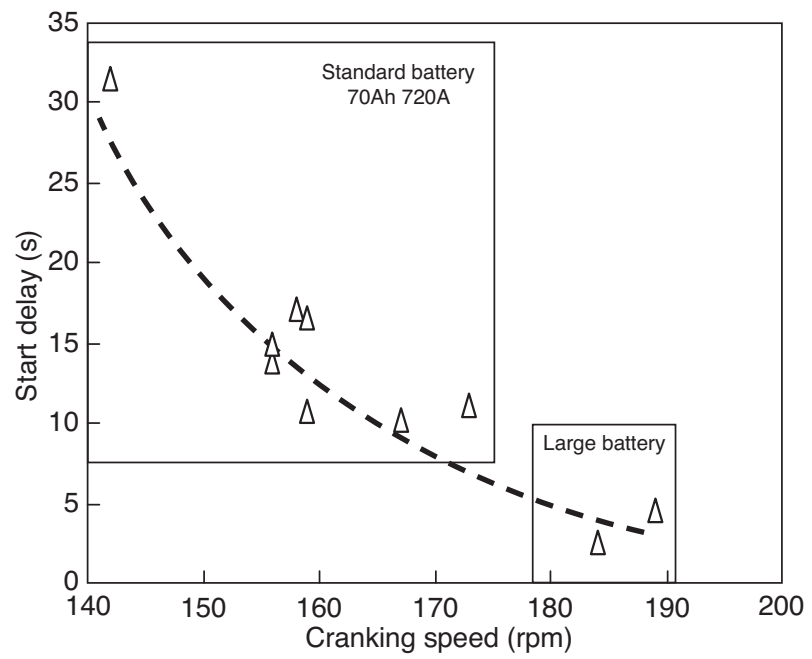

Figure 43

Impact of cranking speed, with batteries presenting various characteristics, on start delay at $-25^{\circ} \mathrm{C}$.

\subsection{Impact of Cranking Speed}

By using during first tests a classical vehicle starter and then a dyno, driving speed during the starting phase increased from about 150 to $200 \mathrm{rpm}$ up to 400 to $1000 \mathrm{rpm}$, during tests at an ambient temperature of $-25^{\circ} \mathrm{C}$ (with preglowing duration $=7 \mathrm{~s}$ ).

A substantial reduction of start delay with the increase in cranking speed can be observed (Fig. 42). Due to the dispersion of results observed below $200 \mathrm{rpm}$, the work was focused on this area, using the vehicle starter with batteries presenting various characteristics: capacity and load level. In this way, cranking speed varied from 140 to $190 \mathrm{rpm}$.

The direct impact of cranking speed on the start delay can be observed in Figure 43. In extreme conditions $\left(-25^{\circ} \mathrm{C}\right)$, an improvement of starter characteristics can drastically decrease the start delay, with the help of a moderate increase in cranking speed.

\section{CONCLUSION}

The reduction of the Compression Ratio (CR) in Diesel engines allows reaching lower values of NOx/PM release, and increasing specific power and torque in warm conditions. However, penalties are expected during cold start operation.

In this paper, start delay is studied in cold start conditions on a low compression ratio (13.7:1) engine compared with a nominal compression ratio (17:1) one. With the low CR, injection settings have to be modified. Earlier starts of injection and increased fuel quantities can generally be 
applied with success to a low compression engine; other settings studied in this paper - such as rail pressure and pilot injection - are more specific to the engine. With such a calibration, it is possible to reach similar start delays to those obtained with nominal CR, keeping the same starting equipment (starter, glow plugs) and the same injector technical definition. If shorter start delays are required, upgrades such as the relative position of the spray and glow plug or technology improvements (cranking speed, glow plug temperature) can be helpful.

Moreover, CFD combustion calculations were performed during the starting operation in ambient then cold conditions. The results are in accordance with optical observations and in-cylinder pressure data recorded on the engine. Correlations between tests and calculations give consistent explanations justifying cold start mechanisms, and first-order phenomena regarding vaporization and combustion. In particular, calculation showed that combustion initiation in this engine does not take place after a direct impact of injector sprays on the glow plug, but after a rotation of vaporized fuel in the bowl, which can justify the necessity to adopt early injection timing (about 20 CAD BTDC).

So, the start ability of a HSDI Diesel engine with low compression ratio (13.7:1) does not seem to be problematic until it reaches very low temperatures $\left(-25^{\circ} \mathrm{C}\right)$. On the other hand, engine behavior appears to be unstable during the idle phase just after start. The techniques such as calculation and visualization developed here will be very helpful to understand the mechanisms and then to improve engine behavior in such conditions. This approach should allow one to achieve the challenge consisting of reducing the compression ratio of future Diesel engines.

\section{ACKNOWLEDGMENTS}

This research was essentially conducted within the framework of a research program funded by the Groupement Scientifique Moteurs (IFP, PSA and Renault).

\section{REFERENCES}

1 Walter B., Gatellier B. (2002) nDevelopment of the High Power NADI ${ }^{\mathrm{TM}}$ Concept Using Dual Mode Combustion to Achieve Zero NOx and Particulate Emissions, SAE paper 2002-01-1744.
2 Zolver M., Klahr D., Bohbot J., Laget O., Torres A. (2003) Reactive CFD in engines with a new unstructured parallel solver, Oil Gas Sci. Technol. 58, 1, 33-46.

3 Colin O., Benkenida A. (2004) The 3-zones extended coherent flame model (ECFM3Z) for computing premixed/diffusion combustion, Oil Gas Sci. Technol. 59, 6, 593-609.

4 Colin O., Pires de Cruz A., Jay S. (2005) Detailed chemistry based auto-ignition model including low temperature phenomena applied to 3-D engine calculations, Proc. Combust. Institut. 30, 2649-2656.

5 Beard P. (2005) Towards a predictive modeling of transient injection conditions of Diesel sprays in DID engines, Proceedings of the ILASS Americas 18th Annual conference, Irvine, USA.

6 Habchi C., Huynh Huu C., Lambert L., Vanhemelryck J.L., Baritaud T. (1997) Modeling Atomization and Break Up in High-Pressure Diesel Sprays, SAE paper 970881.

7 O'Rourke P.J., Amsden A.A. (1996) A Particule Numerical Model for Wall Fluid Dynamics in Port-Injected Engines, SAE paper 961961.

8 O'Rourke P.J., Amsden A.A. (2000) A Spray/Wall Interaction Submodel for the KIVA-3 Wall Film Model, SAE paper 200001-0271.

9 Han Z., Xu Z., Trigui N. (2000) Spray/Wall interaction Models for Multidimentional Engine Simulation, Int. J. Engine Res. 1, 127-146.

10 Han Z., Xu Z. (2004) Wall Film Dynamics Modelling for impinging Sprays in engines, SAE paper 2004-01-0099.

11 Buda F., Bounaceur R., Warth V., Glaude P.A., Fournet R., Battin-Leclerc F. (2005) Progress toward a unified detailed kinetic model for the autoignition of alkanes from $\mathrm{C} 4$ to $\mathrm{C} 10$ between 600 and 1200 K, Combust. Flame 142, 170-186.

12 Han Z., Henein N., Nitu B., Bryzik W. (2001) Diesel Engine Cold Start Combustion Instability and Control Strategy, SAE paper 2001-01-1237.

13 Lindl B., Schmitz H.G. (1999) Cold Start Equipment for Diesel Direct Injection Engines, SAE paper 1999-01-1244.

14 Tsunemoto H., Yamada T., Ishitani H. (1986) Behaviour of Adhering Fuel on Cold Combustion Chamber Wall in Direct Injection Diesel Engine, SAE paper 861235.

15 Stanton D.W., Lippert A.M., Reitz R.D. (1998) Influence of Spray-Wall Interaction and Fuel Films on Cold Starting In Direct Injection Diesel Engines, SAE paper 982584.

16 Liu H., Henein A.N., Bryzik W. (2003) Simulation of Diesel Engines Cold Start, SAE paper 2003-01-0080.

17 Amsden A.A., O’Rourke P.J., Butler T.D. (1989) KIVA-II, a Computer Program for Chemically Reactive Flows with Sprays, Report LA-11560-MS, Los Alamos National Laboratory.

18 Hirt C.W., Amsden A.A., Cook J.L. (1974) J. Comput. Phys. 14, 227.

19 Pracht W.E. (1975) J. Comput. Phys. 17, 132.

Final manuscript received in January 2009

Published online in May 2009 